\title{
Is Vitamin D Deficiency Related to Accumulation of Advanced Glycation End Products, Markers of Inflammation, and Oxidative Stress in Diabetic Subjects?
}

\author{
K. Šebeková, ${ }^{1}$ M. Stürmer, ${ }^{2}$ G. Fazeli, ${ }^{2}$ U. Bahner, ${ }^{3}$ F. Stäb, ${ }^{4}$ and A. Heidland ${ }^{2,3}$ \\ ${ }^{1}$ Comenius University Medical Faculty, 81107 Bratislava, Slovakia \\ ${ }^{2}$ University of Würzburg, 97080 Würzburg, Germany \\ ${ }^{3}$ KfH Nierenzentrum Würzburg, 97080 Würzburg, Germany \\ ${ }^{4}$ Beiersdorf AG, Hamburg, Germany
}

Correspondence should be addressed to A. Heidland; august.heidland@t-online.de

Received 1 November 2014; Revised 12 January 2015; Accepted 27 January 2015

Academic Editor: Jun Ren

Copyright (C 2015 K. Šebeková et al. This is an open access article distributed under the Creative Commons Attribution License, which permits unrestricted use, distribution, and reproduction in any medium, provided the original work is properly cited.

\begin{abstract}
Objectives. In diabetes accumulated advanced glycation end products (AGEs) are involved in the striking cardiovascular morbidity/mortality. We asked whether a hypovitaminosis D associates with an increased formation and toxicity of AGEs in diabetes. Methods. In 276 diabetics $(160 \mathrm{M} / 116 \mathrm{~F}$, age: $65.0 \pm 13.4 ; 43$ type 1,T1DM, and 233 type 2 patients, T2DM) and 121 nondiabetic controls $\left(60 \mathrm{M} / 61 \mathrm{~F}\right.$; age: $58.6 \pm 15.5$ years) routine biochemistry, levels of 25 -hydroxyvitamin $\mathrm{D}_{3}(25-(\mathrm{OH}) \mathrm{D})$, skin autofluorescence (SAF), plasma AGE-associated fluorescence (AGE-FL), $\mathrm{N}^{\varepsilon}$-(carboxymethyl)lysine (CML), soluble receptor for AGEs (sRAGE), soluble vascular adhesion protein-1 (sVAP-1), high sensitive C-reactive protein (hs-CRP), and renal function (eGFR) were determined. Results. In the diabetics SAF and AGE-Fl were higher than those of the controls and correlated with age, duration of diabetes, and degree of renal impairment. In T2DM patients but not in T1DM the age-dependent rise of SAF directly correlated with hs-CRP and sVAP-1. 25-(OH)D levels in diabetics and nondiabetics were lowered to a similar degree averaging $22.5 \mathrm{ng} / \mathrm{mL}$. No relationship between $25-(\mathrm{OH}) \mathrm{D}$ and studied markers except for sVAP-1 was observed in the diabetics. Conclusion. In diabetics hypovitaminosis $\mathrm{D}$ does not augment accumulation of AGEs and studied markers of microinflammation and oxidative stress except for sVAP-1.
\end{abstract}

\section{Introduction}

Advanced glycation end products (AGEs) are a heterogeneous group of compounds implicated in the pathophysiology of aging, diabetes mellitus, and chronic kidney disease (CKD). They are formed by nonenzymatic glycation of proteins, lipids, and nucleic acids and under conditions of oxidative and carbonyl stress $[1,2]$. Other factors involved in accumulation of AGEs are their impaired renal removal in kidney dysfunction [3], consumption of highly heat-treated foods with an elevated AGE content $[4,5]$ and inhalation of tobacco smoke [6]. AGEs exert their deleterious effects directly by modifications of long-lived intra- and extracellular proteins, which affect their structural and functional properties. Cross-linking of collagen promotes vascular stiffness
[7] and also injures the skeletal muscle [8]. Indirect harmful effects arise from interactions of AGEs with their receptors (particularly RAGE) at the cell membrane. RAGE activation induces nuclear transcription factors (e.g., nuclear factor kappa-B, NF- $\kappa \mathrm{B}$ ), generation of oxygen radicals, synthesis of proinflammatory cytokines/chemokines, fibrogenic growth factors (transforming growth factor- $\beta-1$, TGF-beta-1), vascular adhesion molecules and cell proliferation [9], and reduction of nitric oxide (NO) formation [10]. AGEs may also interrupt key steps in reverse cholesterol transport [11]. Beside cardiovascular disturbances, AGE accumulation is linked to an enhanced cancer incidence, in part due to an AGE-induced genomic damage $[12,13]$.

Diabetes mellitus is associated with an excessive accumulation of AGEs [14]. Subsequently a microangiopathy 
(nephropathy, neuropathy, and retinopathy) and an accelerated atherosclerotic vasculopathy (including coronary heart, cerebrovascular, and peripheral artery disease) develop [15]. AGEs may directly contribute to induction or aggravation of diabetes causing progressive insulin secretory defects and pancreatic beta cell deaths [16] and by enhancing insulin resistance via decreased biological activity of glycated insulin [17].

Elevated levels of circulating AGEs such as pentosidine, $\mathrm{N}^{\varepsilon}$-carboxymethyllysine (CML), and AGE-associated fluorescence (AGE-Fl) were related to coronary and peripheral artery disease (PAD), renal damage, and total cardiovascular mortality in the general population [18-20], in particular in patients with type 2 diabetes [21] and end-stage renal disease [22]. The toxic effects of AGEs are partly neutralized by soluble RAGE (sRAGE), which represents the truncated form of the receptor acting as a decoy [23].

In the past several years, a noninvasive measurement of skin AGE-associated autofluorescence (SAF) has been developed. SAF is closely related to AGE accumulation in the tissues and reflects the "long term cumulative metabolic and oxidative stress." SAF is an independent predictor of cardiovascular complications, morbidity, and mortality [24-27].

Similar to the consequences of AGE accumulation, vitamin $\mathrm{D}$ deficiency may be involved in numerous biochemical and clinical disturbances, besides the musculoskeletal disorders induced by secondary hyperparathyroidism [28]. Observational and prospective studies showed associations of vitamin $\mathrm{D}_{3}$ deficiency with cardiovascular disease [29], hypertension (via stimulation of the renin-angiotensinaldosterone system [30-32]), vascular stiffness [33], coronary artery calcification [34, 35] heart hypertrophy, stroke [36], renal damage, autoimmune diseases (type I diabetes, multiple sclerosis, and rheumatoid arthritis) [28], infections (lowered antimicrobial peptide cathelicidin [37]), and impaired cognitive function including Alzheimer disease [38]. Vitamin D deficiency likewise seems to be involved in impaired glucose tolerance or type 2 diabetes [39]. It may predispose to an impaired insulin secretion via the vitamin $\mathrm{D}$ receptor (VDR) in the beta cells of the pancreas [40-42] and an impaired insulin sensitivity, resulting in insulin resistance [43-45]. In type 1 diabetes severe vitamin $\mathrm{D}$ deficiency predicts all-cause mortality [46]. Moreover reduced muscle function may be associated with both vitamin D deficiency [47] and AGE accumulation [8].

Data about potential relationships between vitamin $\mathrm{D}_{3}$ deficiency and AGE accumulation are, so far, scarce. In in vitro studies it was shown that the deleterious effects of AGEmodified albumin on endothelial cells could be prevented by coincubation with calcitriol, the active form of vitamin $\mathrm{D}$ [48]. In diabetic rats administration of vitamin $\mathrm{D}$ reduced systemic oxidative stress and the deposition of AGEs (CML) in the aortic wall [49]. In the current paper we investigated the impact of vitamin D status on the AGE levels in skin and plasma and markers of microinflammation and oxidative stress as well as on muscle function in diabetic patients to elucidate the potential interactions.

\section{Subjects and Methods}

This cross-sectional noninterventional study was conducted according to the Declaration of Helsinki and a protocol approved by the Ethics Committee of the Medical Faculty of the University of Würzburg. Signed written informed consent was obtained from all participants.

A total of 276 consenting diabetic patients (age range: 16-94 years; $18 \%$ type 1 diabetes mellitus, (DM) duration: newly diagnosed to 56 years) visiting the ambulance of the KfH-Kidney Center Würzburg and the Practice of Internal Medicine (Dr. Werner Stürmer) in Würzburg were recruited. Inclusion criteria were type 1 or type $2 \mathrm{DM}$. Control subjects ( $n=121$; age range: $16-96$ years) were recruited from participants of regular check-ups in the same practice during the same time period as well as the staff. Exclusion criteria for both controls and diabetics comprised any acute illness, autoimmune diseases, malignancies, dermatosis, scars and pigment disorders, pregnancy or lactation in women, current smoking (self-reported), use of glucocorticoids, vitamin D supplements (during the last 6 months), regular visits to a solarium, and use of tanning cream (during the last 14 days). Patients with hypertension and/or diabetes were treated according to the current guidelines.

Weight and height were measured and body mass index (BMI) was calculated. SAF was measured on the volar side of the forearm using the AGE-Reader (DiagnOptics BV Groningen, Netherlands) as previously described [21]. Hand-grip muscle strength was measured using the Baseline Hydraulic Hand Dynamometer (White Plains NY, USA).

Venous blood was collected in the morning hours (7.00 to $9.00 \mathrm{~h}$ ), after overnight fasting and analyzed for serum creatinine, haemoglobin Alc (HbAlc, HPLC method, ADAM Alc HA 8180 FAST, Axonlab, Germany), high sensitive C-reactive protein (hs-CRP, nephelometrically, Siemens reagent), and 25(OH)D (electrochemiluminescence immunoassay, ECLIA, Roche, Germany) in a certified laboratory (Labor Limbach, Heidelberg, Germany). Vitamin D deficiency was defined as $25(\mathrm{OH}) \mathrm{D}$ level $<20 \mathrm{ng} / \mathrm{mL}$, vitamin $\mathrm{D}$ insufficiency as $25(\mathrm{OH}) \mathrm{D}$ level $20-30 \mathrm{ng} / \mathrm{mL}$, and vitamin D sufficiency as 25(OH)D level $>30 \mathrm{ng} / \mathrm{mL}$. Abbreviated MDRD formula was used to estimate glomerular filtration rate (eGRF).

Aliquots of plasma were stored at $-80^{\circ} \mathrm{C}$ and transferred on dry ice to a laboratory in Bratislava for determination of total proteins (Vitros 250 analyzer, USA), AGE-associated fluorescence of plasma according to Münch et al. [50], and concentrations of CML (ELISA, Microcoat, Bernried, Germany), sRAGE (ELISA, R\&D Systems, Minneapolis, MN, USA), and soluble vascular receptor adhesion protein-1 (sVAP-1, ELISA, Bender MedSystem Inc., Vienna, Austria) using commercial ELISA kits according to manufacturer's instructions.

Presence of comorbidities (hypertension (HT), coronary heart disease (CHD), and peripheral artery disease (PAD)) was tracked from documentation and was not available for 12 newly diagnosed diabetics.

2.1. Statistical Analysis. Data not distributed normally were logarithmically transformed for statistical analyses. 
TABLE 1: Cohort characteristics.

\begin{tabular}{|c|c|c|c|c|c|c|}
\hline & Controls & All DM patients & $P$ & DM1 patients & DM2 patients & $P$ \\
\hline$N(\%)$ & 121 & 276 & & $43(16 \%)$ & $233(84 \%)$ & \\
\hline Males/females $(n ; \%)$ & $60 / 61(50 \% / 50 \%)$ & $160 / 116(58 \% / 42 \%)$ & $0.12^{\text {chi }}$ & $23 / 20(53 \% / 47 \%)$ & $137 / 96(59 \% / 41 \%)$ & $0.52^{\text {chi }}$ \\
\hline Age (years) & $58.6 \pm 15.1$ & $65.0 \pm 13.4$ & $<0.001$ & $48.6 \pm 1.8$ & $68.0 \pm 9.6$ & $<0.001$ \\
\hline DM duration (yrs) & - & $15.1 \pm 10.7$ & - & $19.5 \pm 13.2$ & $15.0 \pm 10.1$ & 0.10 \\
\hline BMI $\left(\mathrm{kg} / \mathrm{m}^{2}\right)$ & $27.2 \pm 3.3$ & $30.5 \pm 6.1$ & $<0.001$ & $25.4 \pm 3.7$ & $31.4 \pm 6.0$ & $<0.001$ \\
\hline Total protein $(\mathrm{g} / \mathrm{L})$ & $72 \pm 7$ & $72 \pm 7$ & 0.71 & $71 \pm 5$ & $72 \pm 7$ & 0.24 \\
\hline $\mathrm{eGFR}\left(\mathrm{mL} / \mathrm{min} / 1.73 \mathrm{~m}^{2}\right)$ & $84 \pm 16$ & $71 \pm 25$ & $<0.001$ & $83 \pm 26$ & $69 \pm 24$ & $<0.001$ \\
\hline HbAlc (\%) & $5.5 \pm 0.3$ & $7.1 \pm 1.1$ & $<0.001$ & $7.1 \pm 1.1$ & $7.1 \pm 1.1$ & 0.98 \\
\hline Fl-AGEs (AU) & $281 \pm 67$ & $341 \pm 112$ & $<0.001$ & $289 \pm 104$ & $350 \pm 111$ & $<0.001$ \\
\hline SAF (AU) & $2.3 \pm 0.5$ & $2.8 \pm 0.7$ & $<0.001$ & $2.5 \pm 0.7$ & $2.9 \pm 0.7$ & $<0.001$ \\
\hline CML (ng/mL) & $1045 \pm 368$ & $1023 \pm 393$ & 0.71 & $1125 \pm 940$ & $1008 \pm 385$ & 0.12 \\
\hline sRAGE (pg/mL) & $989 \pm 376$ & $936 \pm 497$ & 0.23 & $1133 \pm 638$ & $922 \pm 474$ & 0.30 \\
\hline sVAP-1 (ng/mL) & $409 \pm 166$ & $462 \pm 172$ & 0.049 & $415 \pm 138$ & $469 \pm 176$ & 0.16 \\
\hline hsCRP (mg/L) & $2.0 \pm 2.0$ & $2.7 \pm 2.4$ & 0.001 & $1.9 \pm 1.9$ & $2.9 \pm 2.4$ & 0.004 \\
\hline Grip strength (pounds) & $84 \pm 31$ & $75 \pm 25$ & 0.026 & $85 \pm 32$ & $74 \pm 23$ & 0.09 \\
\hline${ }^{*}$ Hypertension (N/Y; \%) & $88 / 33(73 \% / 27 \%)$ & $96 / 167(37 \% / 63 \%)$ & $<\mathbf{0 . 0 0 1}^{\text {chi }}$ & $23 / 13(53 \% / 47 \%)$ & $73 / 154(32 \% / 68 \%)$ & $<\mathbf{0 . 0 0 1}^{\text {chi }}$ \\
\hline *PAD (N/Y; \%) & $119 / 2(98 \% / 2 \%)$ & $220 / 44(83 \% / 17 \%)$ & $<\mathbf{0 . 0 0 1}^{\text {chi }}$ & $34 / 2(94 \% / 6 \%)$ & $186 / 42(82 \% / 18 \%)$ & $0.054^{\text {chi }}$ \\
\hline${ }^{*} \mathrm{CHD}(\mathrm{N} / \mathrm{Y} ; \%)$ & $117 / 4(97 \% / 3 \%)$ & $213 / 51(81 \% / 19 \%)$ & $<\mathbf{0 . 0 0 1}^{\text {chi }}$ & $33 / 3(92 \% / 8 \%)$ & $180 / 48(79 \% / 21 \%)$ & $0.07^{\text {chi }}$ \\
\hline${ }^{*}$ Total comorbidities (N/Y; \%) & $87 / 34(72 \% / 28 \%)$ & $74 / 190(28 \% / 72 \%)$ & $<0.001^{\text {chi }}$ & $22 / 114(61 \% / 39 \%)$ & $52 / 176(23 \% / 77 \%)$ & $<0.001^{\text {chi }}$ \\
\hline
\end{tabular}

DM1: type 1 diabetes mellitus; DM2: type 2 diabetes mellitus; BMI: body mass index; eGFR: estimated glomerular filtration rate; HbAlc: haemoglobin A1c; AGEFl: advanced glycation end products associated fluorescence of plasma; CML: $\mathrm{N}^{\varepsilon}$-carboxymethyllysine; SAF: skin autofluorescence; sVAP-1: soluble vascular receptor adhesion protein-1; sRAGE: soluble receptor for advanced glycation end products; hsCRP: high sensitive C-reactive protein; Y: yes; N: no; PAD: peripheral artery disease; CHD: coronary heart disease; chi: chi-square; ${ }^{*}$ data missing from 12 subjects.

Descriptive statistics are presented as percentages or means \pm SD. Two sets of data were compared using two-sided Student's $t$-test, for comparison of $\geq 3$ sets of data analysis of variance (ANOVA) with post hoc Scheffe's test was employed. Proportions were compared using chi-square test. Pearson's correlation coefficients were calculated. Multivariate analysis was performed using the General Linear Model (GLM). SPSS statistical software (v. 16.0 for Windows; SPSS, Chicago, Illinois) was used with the significance set at $P<0.05$. The orthogonal projections to latent structures discriminant analysis (OPLS-DA, Simca v.13 software, Umetrics, Umea, Sweden) was used to identify independent variables contributing to separation between subjects with $25(\mathrm{OH}) \mathrm{D}$ deficiency and those with sufficient levels.

\section{Results}

\subsection{Cohort Characteristics}

3.1.1. Nondiabetics versus Diabetic Subjects. Cohort characteristics are given in Table 1. The proportion of females and males, CML, and sRAGE concentrations did not differ significantly between diabetic and control subjects. DM patients were significantly older $(P<0.001)$ and had as expected higher BMI $(P<0.001)$, HbAlc $(P<0.001)$, SAF $(P<0.001)$, hsCRP $(P=0.001)$, AGE-associated fluorescence $(P<0.001)$, and sVAP-1 $(P=0.049)$ levels, presented higher frequency of comorbidities, a lower eGFR $(P<0.001)$, and grip strength $(P=0.026)$ in comparison to controls.
To elucidate the independent effects of age and presence of diabetes, multivariate analysis using the GLM was employed. Selected independent variables did not affect significantly CML levels (Table 2).

3.1.2. Impact of Type of Diabetes. Type 1 diabetic patients were younger $(P<0.001)$ than their type 2 DM counterparts (Table 1). Glycemia was similar in both cohorts $(P=0.98)$ and DM was diagnosed also for a comparable time period $(P=0.10)$. Type 1 and 2 diabetics did not differ significantly in CML, sRAGE, and sVAP-1 levels and produced a similar strength in the hand-grip test. In comparison to type 2 diabetic patients, type 1 diabetics presented lower BMI, AGEspecific fluorescence of plasma, SAF $(P<0.001)$, and hsCRP $(P=0.004)$ levels and higher eGFR $(P<0.001)$. The potential impact of the type of diabetes, its duration, and subjects' age on studied markers was estimated using the GLM. It did not select type of diabetes as independent significant contributor in either setting (Table 3). Duration of diabetes significantly and independently affected eGFR, AGE-Fl, SAF, sVAP-1, and grip strength, while aging was significantly associated with decline in eGFR and rise in AGE-Fl and SAF. However, in case of CML, sVAP-1, sRAGE, and hsCRP the independent variables explained only minor percentage of variability of respective dependent variables.

3.2. $25(\mathrm{OH}) \mathrm{D}$ Status. The mean concentrations of $25(\mathrm{OH}) \mathrm{D}$ were in the lower range of $25(\mathrm{OH}) \mathrm{D}$ insufficiency in 
TABLE 2: Multiple regression, effect of ageing, and presence/absence of DM on selected independent variables.

\begin{tabular}{lccccccccc}
\hline & $25(\mathrm{OH}) D$ & $H b A 1 c$ & $A G E-F l$ & $C M L$ & SAF & sVAP-1 & sRAGE & hsCRP & Grips \\
\hline Corr. m. & 0.84 & $\mathbf{0 . 0 0 1}$ & $\mathbf{0 . 0 0 1}$ & 0.93 & $\mathbf{0 . 0 0 1}$ & $\mathbf{0 . 0 4 5}$ & $\mathbf{0 . 0 1 9}$ & $\mathbf{0 . 0 0 1}$ & $\mathbf{0 . 0 0 1}$ \\
Intercept & 0.001 & $\mathbf{0 . 0 0 1}$ & $\mathbf{0 . 0 0 1}$ & 0.001 & $\mathbf{0 . 0 0 1}$ & $\mathbf{0 . 0 0 1}$ & $\mathbf{0 . 0 0 2}$ & $\mathbf{0 . 0 1 1}$ & $\mathbf{0 . 0 0 1}$ \\
Age & 0.83 & 0.06 & $\mathbf{0 . 0 0 1}$ & 0.90 & $\mathbf{0 . 0 0 1}$ & 0.23 & $\mathbf{0 . 0 0 6}$ & $\mathbf{0 . 0 0 2}$ & $\mathbf{0 . 0 0 1}$ \\
DM st. & 0.62 & $\mathbf{0 . 0 0 1}$ & $\mathbf{0 . 0 0 1}$ & 0.69 & $\mathbf{0 . 0 0 1}$ & 0.10 & 0.20 & $\mathbf{0 . 0 0 7}$ & 0.94 \\
$R^{2}$ & -0.01 & 0.35 & 0.15 & -0.01 & 0.31 & 0.01 & 0.03 & 0.05 & 0.17 \\
\hline
\end{tabular}

25(OH)D: 25(OH)D $\mathrm{D}_{3}$; HbAlc: haemoglobin Alc; AGE-Fl: advanced glycation end products associated fluorescence of plasma; CML: $\mathrm{N}^{\varepsilon}$-carboxymethyllysine; SAF: skin autofluorescence; sVAP-1: soluble vascular receptor adhesion protein-1; sRAGE: soluble receptor for advanced glycation end products; hsCRP: high sensitive C-reactive protein; corr. M.: corrected model; DM st.: diabetic status, classified 0/1 as absence/presence; italics: due to not normal distribution statistics performed on logarithmically transformed data. In case of sVAP-1, sRAGE, and hsCRP model was significant although age and presence of diabetes explained $<5 \%$ in their variability $\left(R^{2}\right)$.

TABLE 3: Multiple regression, effect of ageing, and duration of diabetes and DM type on selected independent variables.

\begin{tabular}{lccccccccc}
\hline & $25(\mathrm{OH}) D$ & $e G F R$ & $A G E-F l$ & $C M L$ & SAF & sVAP-1 & $s R A G E$ & hsCRP & Grips \\
\hline Corr. M. & 0.75 & $\mathbf{0 . 0 0 1}$ & $\mathbf{0 . 0 0 1}$ & $\mathbf{0 . 0 4 9}$ & $\mathbf{0 . 0 0 1}$ & $\mathbf{0 . 0 0 2}$ & $\mathbf{0 . 0 0 4}$ & $\mathbf{0 . 0 1 6}$ & $\mathbf{0 . 0 0 1}$ \\
Intercept & 0.001 & $\mathbf{0 . 0 0 1}$ & $\mathbf{0 . 0 0 1}$ & $\mathbf{0 . 0 0 1}$ & $\mathbf{0 . 0 0 1}$ & $\mathbf{0 . 0 0 1}$ & $\mathbf{0 . 0 0 1}$ & 0.44 & $\mathbf{0 . 0 0 1}$ \\
DM dur. & 0.92 & $\mathbf{0 . 0 0 1}$ & $\mathbf{0 . 0 0 1}$ & 0.42 & $\mathbf{0 . 0 0 3}$ & $\mathbf{0 . 0 2 7}$ & $\mathbf{0 . 0 0 8}$ & 0.89 & $\mathbf{0 . 0 0 1}$ \\
Age & 0.28 & $\mathbf{0 . 0 0 1}$ & $\mathbf{0 . 0 0 1}$ & 0.09 & $\mathbf{0 . 0 0 1}$ & 0.09 & 0.29 & 0.28 & 0.08 \\
DM type & 0.52 & 0.84 & 0.24 & 0.60 & 0.71 & 0.28 & 0.38 & 0.07 & 0.47 \\
$R^{2}$ & -0.01 & 0.27 & 0.20 & 0.03 & 0.24 & 0.06 & 0.05 & 0.03 & 0.17 \\
\hline
\end{tabular}

25(OH)D: 25(OH) $\mathrm{D}_{3}$; eGFR: estimated glomerular filtration rate; AGE-Fl: advanced glycation end products associated fluorescence of plasma; CML: $\mathrm{N}^{\varepsilon}$ carboxymethyllysine; SAF: skin autofluorescence; sVAP-1: soluble vascular receptor adhesion protein-1; sRAGE: soluble receptor for advanced glycation end products; hsCRP: high sensitive C-reactive protein; corr. M.: corrected model; DM type: type 1 or type 2 diabetes; italics: due to not normal distribution statistics performed on logarithmically transformed data. In case of CML, sRAGE and hsCRP model was significant although age and type of diabetes explained $\leq 5 \%$ in their variability $\left(R^{2}\right)$.

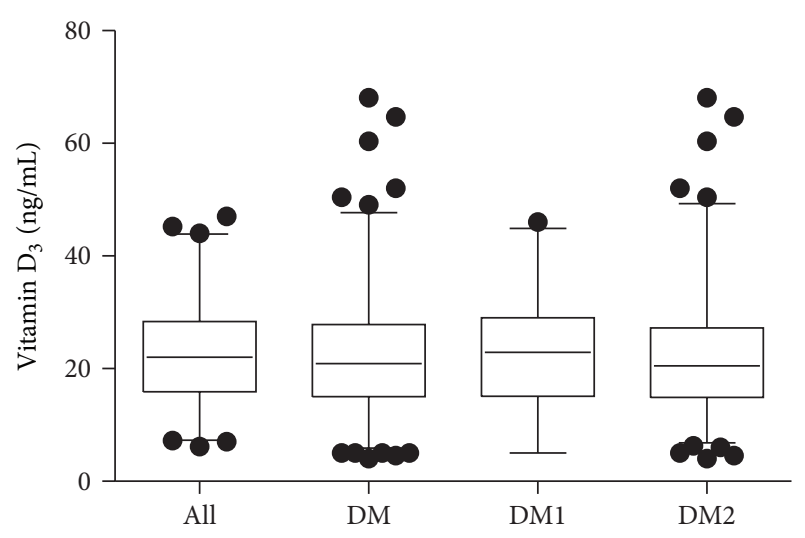

Figure 1: 25(OH)D concentration in the controls, diabetic patients (DM), type 1 (DM1) or type 2 (DM2) diabetics. Data are presented as median, interquartile range, and 95\% confidence interval (CI). Dots represent outliers beyond $95 \% \mathrm{CI}$.

the controls and diabetics and did not differ significantly between the groups (Figure 1). Age and presence/absence of diabetes in the whole cohort, or age, duration, and type of diabetes in diabetics showed no significant impact on 25(OH)D levels (Tables 2 and 3).

In the controls no significant relationships between any other tested variable and $25(\mathrm{OH}) \mathrm{D}$ levels were revealed (Table 4). In diabetic subjects HbAlc, CML, and sVAP-1 levels correlated inversely, and grip strength directly with $25(\mathrm{OH}) \mathrm{D}$ concentrations. Similar to observations in the whole cohort of diabetics, significant associations between $\mathrm{HbAlc}$, CML, sVAP-1, levels, and grip strength on the one hand and $25(\mathrm{OH}) \mathrm{D}$ concentration on the other were revealed in type 2 diabetics, while in type 1 diabetics only the relation between CML or grip strength and $25(\mathrm{OH}) \mathrm{D}$ was significant (Table 4). $25(\mathrm{OH}) \mathrm{D}$ levels showed no significant relationship with SAF either in type 1 and type 2 diabetics (Figure 2(a)) or in the controls (Figure 2(b)).

The prevalence of $25(\mathrm{OH}) \mathrm{D}$ deficiency ( $47 \%$ versus $44 \%$ ), insufficiency (32\% versus 35\%), and sufficient levels (21\% versus $21 \%)$ was similar among diabetics and controls $\left(P_{\text {chi }}=\right.$ 0.76).

A multivariate analysis using the OPLS-DA model was employed to elucidate which variables contribute to separation between $25(\mathrm{OH}) \mathrm{D}$ deficient subjects and those presenting sufficient levels.

In the control group a satisfactory separation between $25(\mathrm{OH}) \mathrm{D}$ deficient subjects and those with satisfactory levels was obtained (Figure 3(a)). The calculated model described $76 \%$ of variability $\left(R^{2}\right)$ with an acceptable predictivity $\left(Q^{2}=\right.$ 0.65 ). Loading scatter plot (Figure 3(b)) and VIP plot (Variables Important for Projection, Figure 3(c)) suggests that $25(\mathrm{OH}) \mathrm{D}$ deficient controls present lower total protein $(\mathrm{VIP}=2.1)$ and sVAP-1 $(\mathrm{VIP}=1.1)$ and higher CML $(\mathrm{VIP}=$ 1.0) levels. AGE-Fl, sRAGE (lower in $25(\mathrm{OH}) \mathrm{D}$ deficient subjects), and BMI (higher in $25(\mathrm{OH}) \mathrm{D}$ deficient subjects; VIP values between 0.7 and 0.5 ) represent variables potentially important for the separation between groups. Moreover, females tended to be more frequent in the $25(\mathrm{OH}) \mathrm{D}$ deficient group. Variables listed to the right from BMI on the VIP 
TABLE 4: Pearson correlation coefficients independent variables to $25(\mathrm{OH}) \mathrm{D}_{3}$.

\begin{tabular}{lccccccc}
\hline & \multicolumn{2}{c}{ Controls } & \multicolumn{2}{c}{ DM patients } & \multicolumn{2}{c}{ DM1 } & \multicolumn{2}{c}{ DM2 } \\
& $r$ & $P$ & $r$ & $P$ & $r$ & $P$ & -0.077 \\
ln age & 0.107 & 0.24 & -0.065 & 0.28 & -0.097 & 0.54 & 0.24 \\
ln DM duration & NA & NA & NA & NA & 0.201 & 0.20 & -0.057 \\
BMI & 0.049 & 0.65 & -0.073 & 0.23 & 0.085 & 0.59 & -0.105 \\
eGFR & 0.082 & 0.50 & 0.051 & 0.42 & 0.028 & 0.87 & 0.066 \\
ln HbA1c & 0.060 & 0.62 & -0.122 & $\mathbf{0 . 0 4 3}$ & -0.025 & 0.087 & -0.135 \\
ln Fl-AGEs & 0.072 & 0.44 & 0.099 & 0.10 & 0.087 & 0.58 & 0.104 \\
ln CML & -0.185 & 0.20 & -0.197 & $\mathbf{0 . 0 0 6}$ & -0.444 & $\mathbf{0 . 0 2 6}$ & -0.177 \\
ln sRAGE & -0.062 & 0.67 & -0.027 & 0.71 & -0.319 & 0.12 & -0.007 \\
sVAP-1 & 0.040 & 0.79 & -0.199 & $\mathbf{0 . 0 0 5}$ & 0.263 & 0.20 & -0.184 \\
ln hsCRP & 0.004 & 0.97 & -0.019 & 0.76 & 0.150 & 0.35 & -0.020 \\
ln Grip & 0.112 & 0.30 & 0.196 & $\mathbf{0 . 0 0 2}$ & 0.506 & $\mathbf{0 . 0 0 3}$ & $\mathbf{0 . 0 1 6}$ \\
\hline
\end{tabular}

DM: diabetes mellitus; DM1: type 1 diabetes mellitus; DM2: type 2 diabetes mellitus; ln: logarithmically transformed data; BMI: body mass index; eGFR: estimated glomerular filtration rate; HbAlc: haemoglobin Alc; AGE-Fl: advanced glycation end products associated fluorescence of plasma; CML: $\mathrm{N}^{\varepsilon}$ carboxymethyllysine; sRAGE: soluble receptor for advanced glycation end products; sVAP-1: soluble vascular receptor adhesion protein-1; hsCRP: high sensitive C-reactive protein.

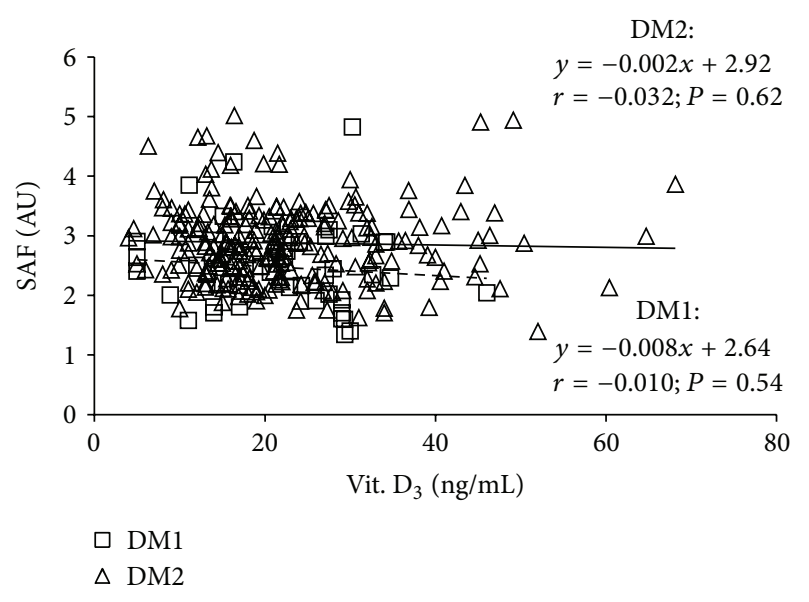

(a)

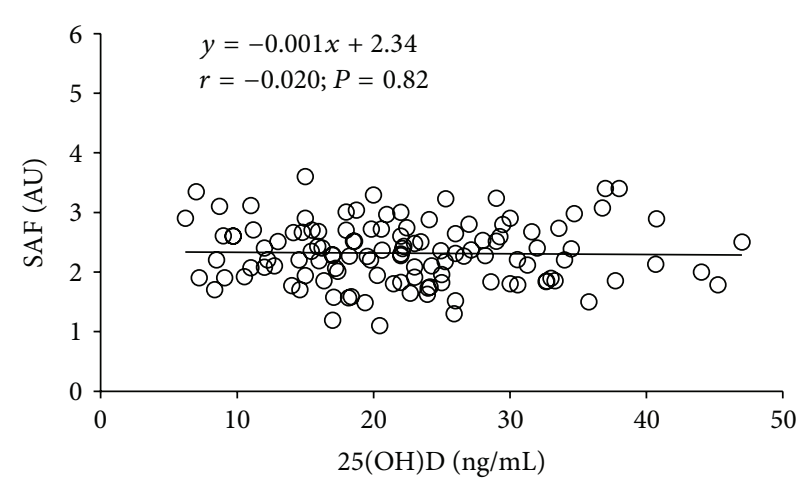

(b)

FIGURE 2: Relationship between skin autofluorescence (SAF) and 25(OH)D levels in type 1 and type 2 diabetics (a) and control subjects (b). DM1: type 1 diabetes mellitus; DM2: type 2 diabetes mellitus; dotted line represents a regression in cohort of type 1 diabetics; solid line represents a regression in cohort of type 2 diabetics.

plot (VIP < 0.5; Figure 3(c)) placed in the vicinity of the intersection of $x$ - and $y$-axis and zero $y$-axis on loading scatter plot (Figure 3(b)) do not have discriminatory power in this model.

However, except for 25(OH)D levels, the $t$-test did not indicate significance, only trends corresponding to results of the multivariate analysis (Table 5).

In the diabetic cohort OPLS-DA analysis revealed a satisfactory separation between the $25(\mathrm{OH}) \mathrm{D}$ deficient and sufficient subjects (Figure 4(a)), with $R^{2}=0.71$ and $Q^{2}=$ 0.64. Loading scatter (Figure 4(b)) and VIP (Figure 4(c)) plots suggest that $25(\mathrm{OH}) \mathrm{D}$ deficient diabetics present higher $\mathrm{CML}$, total protein levels, and a weaker grip strength (VIP = 1.0, all). The levels of sVAP-1 (higher, VIP $=0.9$ ) and AGE-Fl (lower, VIP $=0.7$ ) represent variables potentially contributing to separation. 25(OH)D deficient diabetics comprised more females and fewer subjects suffering from CHD i compared to those presenting sufficient $25(\mathrm{OH}) \mathrm{D}$ levels. HbAlc, BMI, eGFR, sRAGE, age, and presence of hypertension or PAD did not show discriminatory power (Figures $4(\mathrm{~b})$ and $4(\mathrm{c})$ ).

Between-group comparison using the $t$-test confirmed the results indicated in multivariate analysis: $25(\mathrm{OH}) \mathrm{D}$ deficient diabetics presented higher CML, sVAP-1, and total proteins levels; lower AGE-Fl and grip strength and lower prevalence of CHD (Table 5). The impact of inflammation and SAF to the $25(\mathrm{OH}) \mathrm{D}$ levels was further approximated as relationship between $\operatorname{Ln}($ hsCRP/SAF) and 25(OH)D. No significant association was revealed either in diabetics or in the controls (Figures 5(a) and 5(b)). However, Ln(sVAP-1/SAF) correlated inversely in all diabetic patients $(y=-0.006 x-0.006$; 


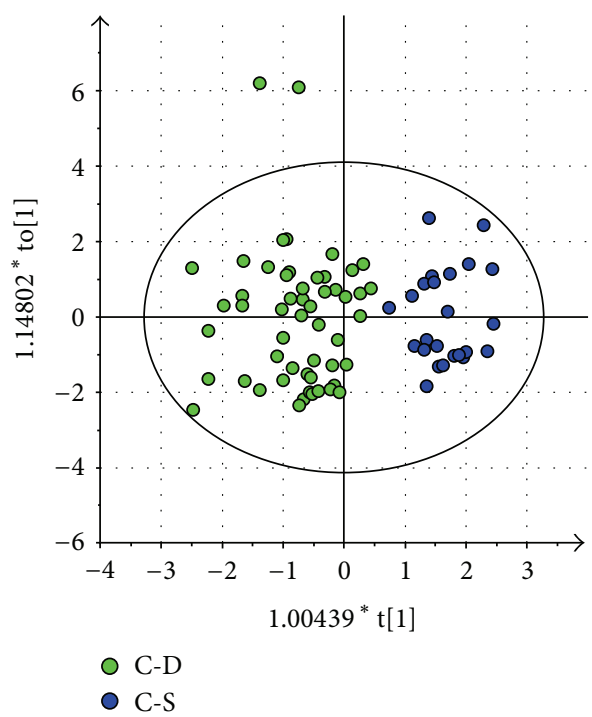

(a)

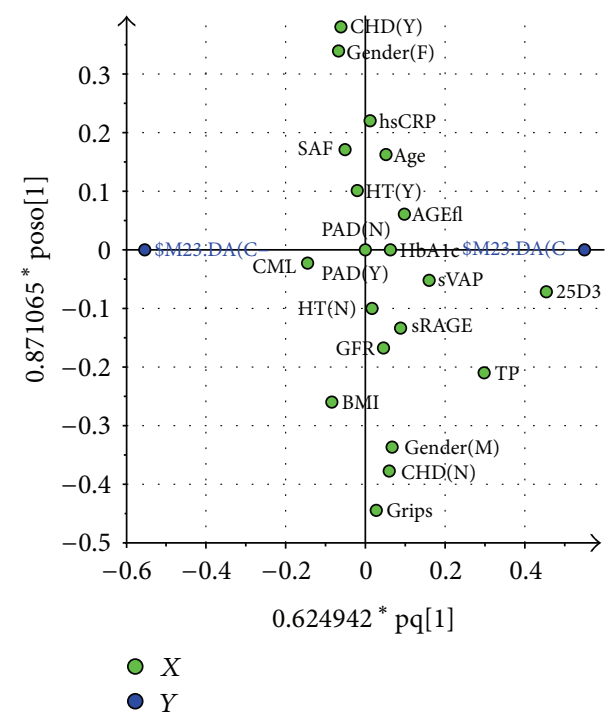

(b)

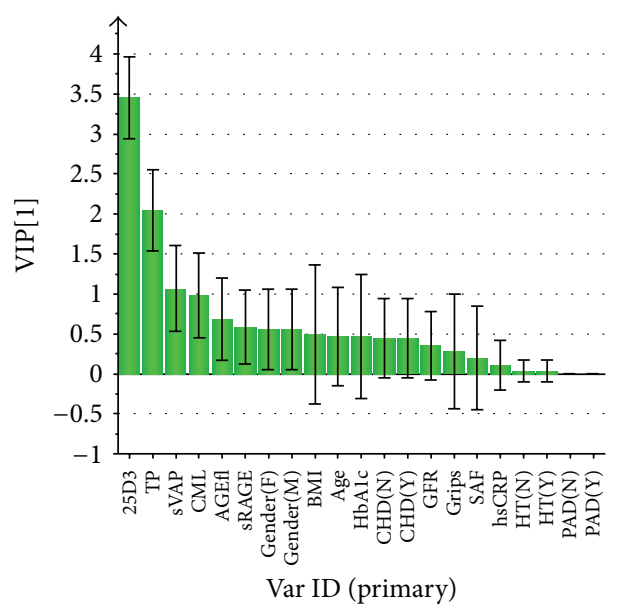

(c)

FIGURE 3: Multivariate analysis data from OPLS-DA model comparing $25(\mathrm{OH}) \mathrm{D}$ deficient nondiabetic subjects $(25(\mathrm{OH}) \mathrm{D}<20 \mathrm{ng} / \mathrm{mL}) \mathrm{with}$ those presenting sufficient levels $(25(\mathrm{OH}) \mathrm{D}>30 \mathrm{ng} / \mathrm{mL})$. (a) Score scatter plot of $25(\mathrm{OH}) \mathrm{D}$ deficient controls $(\mathrm{C}-\mathrm{D}$, green squares) and those presenting sufficient 25(OH)D levels (C-S, blue squares). Scores are orthogonal (=completely independent from each other), representing new variables summarizing the input of all determined variables (herein gender, presence or absence of comorbidities, age, SAF, and biochemical variables) so that one score vector corresponds to one subject, having its own score vector. Observations situated far outside Hotelling's T2 tolerance ellipse are outliers. Model reveals separation of $25(\mathrm{OH}) \mathrm{D}$ deficient and sufficient subjects (separation in direction of $x$-axis). Separation in direction of $y$-axis represents within group variability. (b) Loading scatter plot of $25(\mathrm{OH}) \mathrm{D}$ deficient controls and those presenting sufficient $25(\mathrm{OH}) \mathrm{D}$ levels. Dummy variables (blue circles) characterize the respective 2 groups categorized according to $25(\mathrm{OH}) \mathrm{D}$ levels, deficient group at left, and sufficient one at right side of the plot. Vitamin $\mathrm{D}_{3}(25 \mathrm{D} 3)$ adjacent to dummy variable representing $25(\mathrm{OH}) \mathrm{D}$ sufficient group represents the most significant component with discriminatory power determining the separation between the groups; being situated in the vicinity of vitamin D sufficient group presenting dummy variable it indicates that it is higher in this group. $25(\mathrm{OH}) \mathrm{D}$ deficient subjects also tend to present higher CML levels (positioned in vicinity of respective dummy variable), and lower total protein and sVAP1 levels (far opposite, right to respective dummy). Variables positioned near to intersect and on $y$-axis are similar in $25(\mathrm{OH}) \mathrm{D}$ deficient and sufficient groups and thus do not contribute to between-group separation. (c) Plot of variables of importance contributing to betweengroup separation among 25(OH)D deficient controls and those presenting sufficient 25(OH)D levels. Plot of variables importance for the projection (VIP) summarizes the importance of the variables both to explain $X$ and to correlate with dummy variables (in (a), and (b)). VIP values $>1$ indicate "important" $X$ variables, $<0.5$ "unimportant" $X$ variables, in the "grey interval" (0.5-to- 1$)$ the importance depends on the sample size. This plot confirms the OPLS-DA loadings scatter plot (b), showing that the variables adjacent to the origin in the former plot do not contribute to between-group separation significantly. Abbreviations used in (b) and (c): 25D3: $25(\mathrm{OH})$ vitamin $\mathrm{D}_{3}$; TP: plasma total protein concentration; sVAP: soluble vascular receptor adhesion protein-1; CML: $\mathrm{N}^{\varepsilon}$-carboxymethyllysine; AGE-fl: advanced glycation end products associated fluorescence of plasma; sRAGE: soluble receptor for advanced glycation end products; F: female; M: male; BMI: body mass index; HbAlc: glycated hemoglobin A1c; DM1: type 1 diabetes mellitus; DM2: type 2 diabetes mellitus; eGFR: estimated glomerular filtration rate; CHD: coronary heart disease; N: no, absent; Y: yes, present; GFR: estimated glomerular filtration rate; grips: grip strength; SAF: skin autofluorescence; AOPPs: advanced oxidation protein products; hsCRP: high sensitive C-reactive protein; HT: hypertension; PAD: peripheral artery disease. 


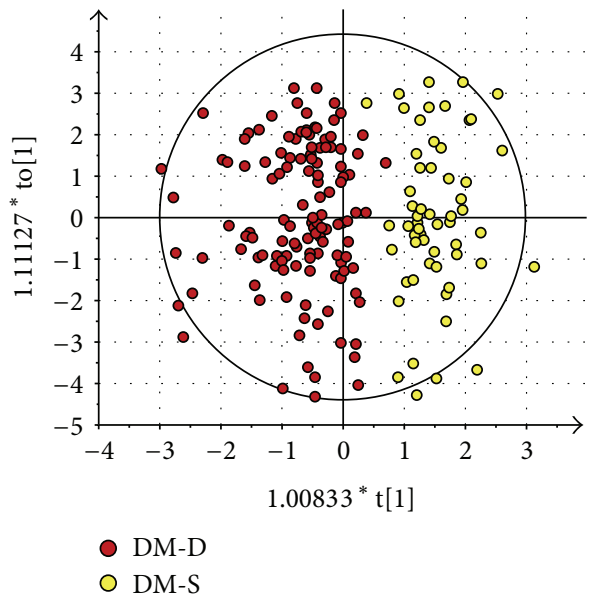

(a)

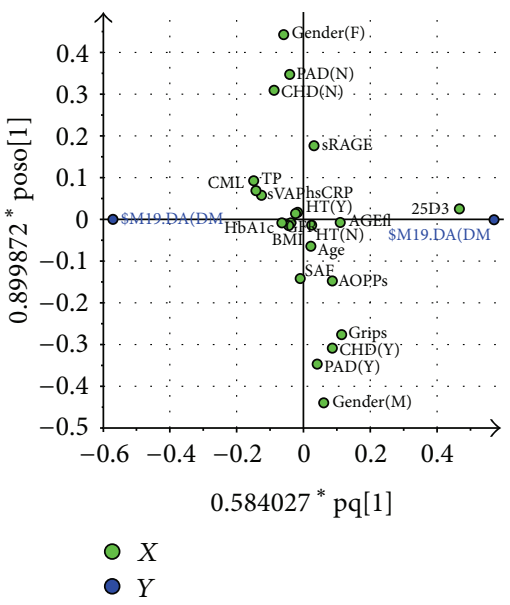

(b)

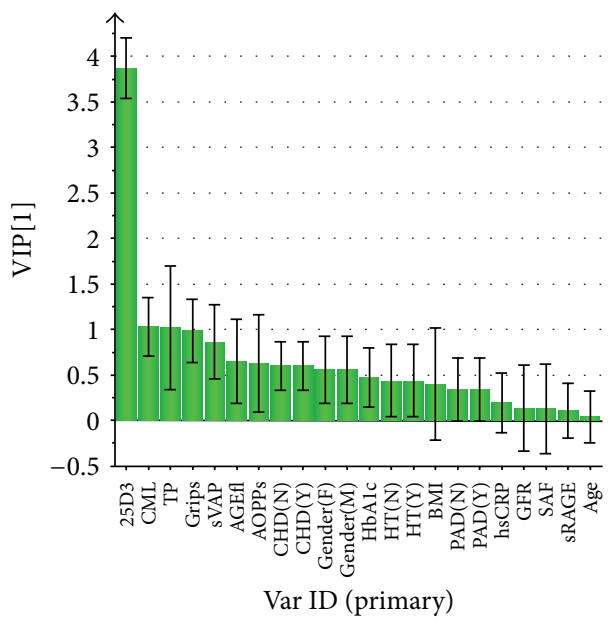

(c)

Figure 4: Multivariate analysis data from OPLS-DA model comparing $25(\mathrm{OH}) \mathrm{D}$ deficient diabetic patients $(25(\mathrm{OH}) \mathrm{D}<20 \mathrm{ng} / \mathrm{mL})$ with those presenting sufficient levels $(25(\mathrm{OH}) \mathrm{D}>30 \mathrm{ng} / \mathrm{mL})$. (a) Score scatter plot of $25(\mathrm{OH}) \mathrm{D}$ deficient diabetic patients (DM-D, red circles) and those presenting sufficient 25(OH)D levels (DM-S, yellow circles). Scores are orthogonal (=completely independent from each other), representing new variables summarizing the input of all determined variables (herein gender, presence or absence of comorbidities, age, SAF, and biochemical variables) so that one score vector corresponds to one subject, having its own score vector. Observations situated far outside Hotelling's T2 tolerance ellipse are outliers. Model reveals separation of 25(OH)D deficient and sufficient diabetic subjects (separation in direction of $x$-axis). Separation in direction of $y$-axis represents within group variability. (b) Loading scatter plot of 25(OH)D deficient diabetic subjects and those presenting sufficient 25(OH)D levels. Dummy variables (blue circles) characterize the respective 2 groups categorized according to $25(\mathrm{OH}) \mathrm{D}$ levels, deficient group at left, and sufficient one at right side of the plot. Vitamin $\mathrm{D}_{3}(25 \mathrm{D} 3)$ adjacent to dummy variable representing $25(\mathrm{OH}) \mathrm{D}$ sufficient group represents the most significant component with discriminatory power determining the separation between the groups; being situated in the vicinity of vitamin D sufficient group presenting dummy variable it indicates that it is higher in this group. 25(OH)D deficient subjects also tend to present higher CML, total protein and sVAP-1 levels (positioned in vicinity of respective dummy variable), and lower AGE-associated fluorescence of plasma, AOPPs and grip strength (far opposite, right to respective dummy). Variables positioned near to intersect and on $y$-axis are similar in $25(\mathrm{OH}) \mathrm{D}$ deficient and sufficient groups and thus do not contribute to between-group separation. (c) Plot of variables of importance contributing to between-group separation among $25(\mathrm{OH}) \mathrm{D}$ deficient controls and those presenting sufficient $25(\mathrm{OH}) \mathrm{D}$ levels. Plot of variables importance for the projection (VIP) summarizes the importance of the variables both to explain $X$ and to correlate with dummy variables (in (a), and (b)). VIP values $>1$ indicate "important" $X$ variables, $<0.5$ "unimportant" $X$ variables, in the "grey interval" (0.5-to-1) the importance depends on the sample size. This plot confirms the OPLS-DA loadings scatter plot (b), showing that the variables adjacent to the origin in the former plot do not contribute to between-group separation significantly. Abbreviations used in Figures 3(b) and 3(c): 25D3: 25(OH) vitamin $\mathrm{D}_{3}$; TP: plasma total protein concentration; sVAP: soluble vascular receptor adhesion protein-1; CML: $\mathrm{N}^{\varepsilon}$-carboxymethyllysine; AGEfl: advanced glycation end products associated fluorescence of plasma; sRAGE: soluble receptor for advanced glycation end products; F: female; M: male; BMI: body mass index; HbAlc: glycated hemoglobin A1c; DM1: type 1 diabetes mellitus; DM2: type 2 diabetes mellitus; eGFR: estimated glomerular filtration rate; CHD: coronary heart disease; N: no, absent; Y: yes, present; GFR: estimated glomerular filtration rate; grips: grip strength; SAF: skin autofluorescence; AOPPs: advanced oxidation protein products; hsCRP: high sensitive C-reactive protein; HT: hypertension; PAD: peripheral artery disease. 
TABle 5: Pertinent data of the controls and diabetic patients with $25(\mathrm{OH}) \mathrm{D}_{3}$ deficiency $\left(25(\mathrm{OH}) \mathrm{D}_{3}<20 \mathrm{ng} / \mathrm{mL}\right)$ and sufficient levels $\left(25(\mathrm{OH}) \mathrm{D}_{3}>30 \mathrm{ng} / \mathrm{mL}\right)$.

\begin{tabular}{|c|c|c|c|c|c|c|}
\hline & \multicolumn{3}{|c|}{ Controls } & \multicolumn{3}{|c|}{ DM subjects } \\
\hline & $25(\mathrm{OH}) \mathrm{D}<20 \mathrm{ng} / \mathrm{mL}$ & $25(\mathrm{OH}) \mathrm{D}>30 \mathrm{ng} / \mathrm{mL}$ & $P$ & $25(\mathrm{OH}) \mathrm{D}<20 \mathrm{ng} / \mathrm{mL}$ & $25(\mathrm{OH}) \mathrm{D}>30 \mathrm{ng} / \mathrm{mL}$ & $P$ \\
\hline $\bar{N}$ & 53 & 25 & NA & 130 & 58 & NA \\
\hline $\mathrm{M} / \mathrm{F}(n ; \%)$ & $23 / 30(43 \% / 57 \%)$ & $15 / 10(60 \% / 40 \%)$ & $0.17^{\mathrm{chi}}$ & $71 / 59(55 \% / 45 \%)$ & $39 / 19(67 \% / 33 \%)$ & $0.10^{\text {chi }}$ \\
\hline Age (years) & $58.5 \pm 17.1$ & $62.6 \pm 13.5$ & 0.23 & $65.9 \pm 13.3$ & $65.5 \pm 11.1$ & 0.94 \\
\hline DM duration (yrs) & NA & NA & & $15.5 \pm 10.7$ & $14.7 \pm 10.6$ & 0.63 \\
\hline BMI $\left(\mathrm{kg} / \mathrm{m}^{2}\right)$ & $27.6 \pm 3.6$ & $28.6 \pm 3.5$ & 0.33 & $31.2 \pm 7.1$ & $29.7 \pm 4.6$ & 0.18 \\
\hline Total protein $(\mathrm{g} / \mathrm{L})$ & $74 \pm 8$ & $70 \pm 6$ & 0.17 & $74 \pm 7$ & $70 \pm 7$ & 0.015 \\
\hline $\mathrm{eGFR}\left(\mathrm{mL} / \mathrm{min} / 1.73 \mathrm{~m}^{2}\right)$ & $83 \pm 12$ & $84 \pm 12$ & 0.71 & $70 \pm 26$ & $69 \pm 23$ & 0.70 \\
\hline $25(\mathrm{OH}) \mathrm{D}_{3}(\mathrm{ng} / \mathrm{mL})$ & $14.4 \pm 3.9$ & $35.5 \pm 4.8$ & $<0.001$ & $13.9 \pm 3.9$ & $38.4 \pm 8.7$ & $<0.001$ \\
\hline HbAlc (\%) & $5.5 \pm 0.3$ & $5.5 \pm 0.3$ & 0.53 & $7.2 \pm 1.2$ & $6.9 \pm 1.0$ & 0.17 \\
\hline Fl-AGEs (AU) & $272 \pm 181$ & $291 \pm 344$ & 0.06 & $329 \pm 108$ & $368 \pm 139$ & 0.05 \\
\hline SAF (AU) & $2.3 \pm 0.5$ & $2.3 \pm 0.5$ & 0.85 & $2.9 \pm 0.7$ & $2.8 \pm 0.8$ & 0.16 \\
\hline $\mathrm{CML}(\mathrm{ng} / \mathrm{mL})$ & $1098 \pm 398$ & $930 \pm 391$ & 0.27 & $1090 \pm 433$ & $899 \pm 236$ & 0.130 \\
\hline sRAGE (pg/mL) & $988 \pm 400$ & $1070 \pm 404$ & 0.53 & $947 \pm 550$ & $949 \pm 493$ & 0.89 \\
\hline hsCRP (mg/L) & $2.1 \pm 2.4$ & $1.6 \pm 1.4$ & 0.85 & $2.8 \pm 2.6$ & $2.5 \pm 2.0$ & 0.59 \\
\hline sVAP-1 (ng/mL) & $406 \pm 152$ & $419 \pm 177$ & 0.38 & $488 \pm 174$ & $430 \pm 181$ & 0.040 \\
\hline Grip strength (pounds) & $81 \pm 33$ & $84 \pm 26$ & 0.50 & $70 \pm 22$ & $80 \pm 23$ & 0.007 \\
\hline${ }^{*}$ Hypertension (N/Y; \%) & $38 / 15(72 \% / 28 \%)$ & $17 / 8(68 \% / 32 \%)$ & $0.74^{\text {chi }}$ & $39 / 84(32 \% / 68 \%)$ & $23 / 33(41 \% / 59 \%)$ & $0.22^{\text {chi }}$ \\
\hline${ }^{*} \mathrm{PAD}(\mathrm{N} / \mathrm{Y} ; \%)$ & $53 / 0(100 \% / 0 \%)$ & $24 / 1(96 \% / 4 \%)$ & $0.70^{\text {chi }}$ & $108 / 15(88 \% / 12 \%)$ & $46 / 10(82 \% / 18 \%)$ & $0.31^{\text {chi }}$ \\
\hline${ }^{*} \mathrm{CHD}(\mathrm{N} / \mathrm{Y} ; \%)$ & $51 / 2(96 \% / 4 \%)$ & $24 / 1(96 \% / 4 \%)$ & $0.56^{\mathrm{chi}}$ & $102 / 21(83 \% / 17 \%)$ & $40 / 16(71 \% / 29 \%)$ & $0.08^{\text {chi }}$ \\
\hline${ }^{*}$ Total comorb. (N/Y; \%) & $38 / 15(72 \% / 28 \%)$ & $17 / 8(68 \% / 32 \%)$ & $0.74^{\text {chi }}$ & $34 / 89(28 \% / 72 \%)$ & $18 / 40(29 \% / 71 \%)$ & $0.64^{\text {chi }}$ \\
\hline
\end{tabular}

DM: diabetes mellitus; M: males; F: females; BMI: body mass index; eGFR: estimated glomerular filtration rate; HbAlc: haemoglobin Alc; AGE-Fl: advanced glycation end products associated fluorescence of plasma; AU: arbitrary units; SAF: skin autofluorescence; CML: $\mathrm{N}^{\varepsilon}$-carboxymethyllysine; sRAGE: soluble receptor for advanced glycation end products; hsCRP: high sensitive C-reactive protein; sVAP-1: soluble vascular receptor adhesion protein-1; Y: yes; N: no; PAD: peripheral artery disease; CHD: coronary heart disease; comorb.: comorbidities; chi: chi-square; ${ }^{*}$ data from 7 diabetics not available.

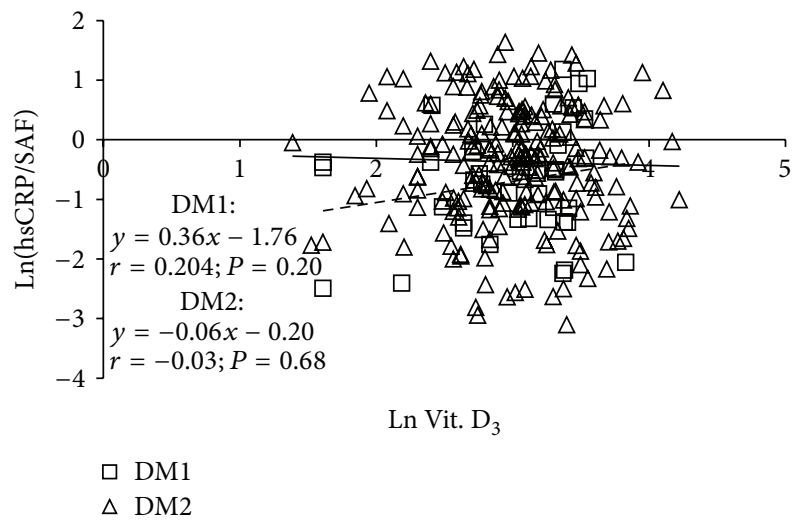

(a)

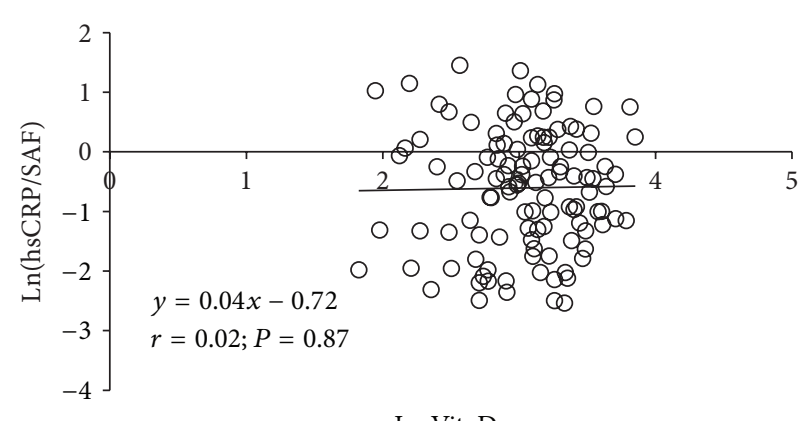

Ln Vit. $\mathrm{D}_{3}$

(b)

Figure 5: Regression of $\ln (\mathrm{hsCRP} / \mathrm{SAF})$ over 25(OH)D concentration in type 1 and type 2 diabetics (a) and control subjects (b). DM1: type 1 diabetes mellitus; DM2: type 2 diabetes mellitus; dotted line represents a regression in cohort of type 1 diabetics; solid line represents a regression in cohort of type 2 diabetics.

$r=0.148 ; P=0.040)$ on account of the type 2 diabetics (Figure 4(a)). In type 1 diabetics and control subjects significance was not reached (Figures 6(a) and 6(b)).

3.3. Markers of Advanced Glycation End Products. In type 1 and 2 diabetics an age-dependent rise in AGE-associated fluorescence of plasma was described by almost parallel lines $(y=3.6 \times$ age $+113, r=0.636, P<0.001$ and $y=$ $3.2 \times$ age $+132, r=0.272, P<0.001$ ), (Figure $7(\mathrm{a})$ ) and that of SAF by fully parallel lines $(y=0.027 \times$ age $+1.17, r=0.671$, $P<0.001$ and $y=0.027 \times$ age $+1.03, r=0.397, P<0.001$, resp.) (Figure $8(a))$. GLM revealed significant impact of age and diabetes duration but not of type of diabetes on SAF and AGE-Fl (Table 3). 


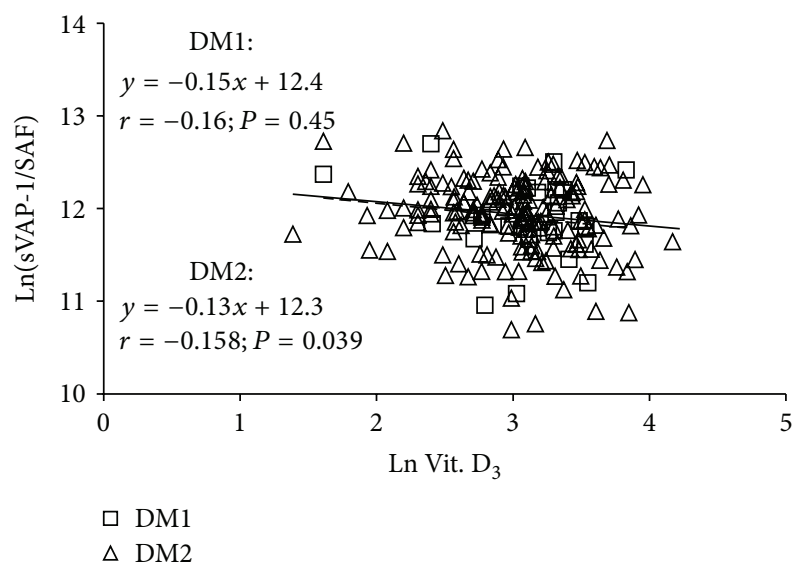

(a)

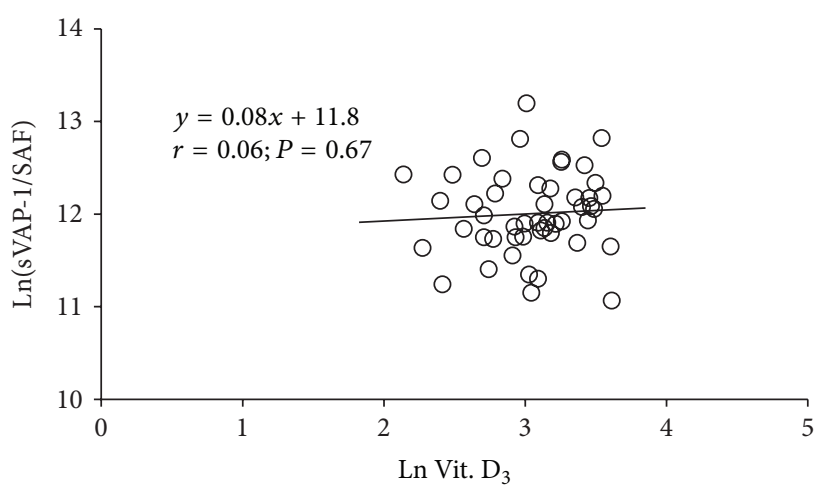

(b)

FIGURE 6: Regression of $\ln (\mathrm{sVAP}-1 / \mathrm{SAF})$ over 25(OH)D concentration in type 1 and type 2 diabetics (a) and control subjects (b). DM1: type 1 diabetes mellitus; DM2: type 2 diabetes mellitus; dotted line represents a regression in cohort of type 1 diabetics; solid line represents a regression in cohort of type 2 diabetics.

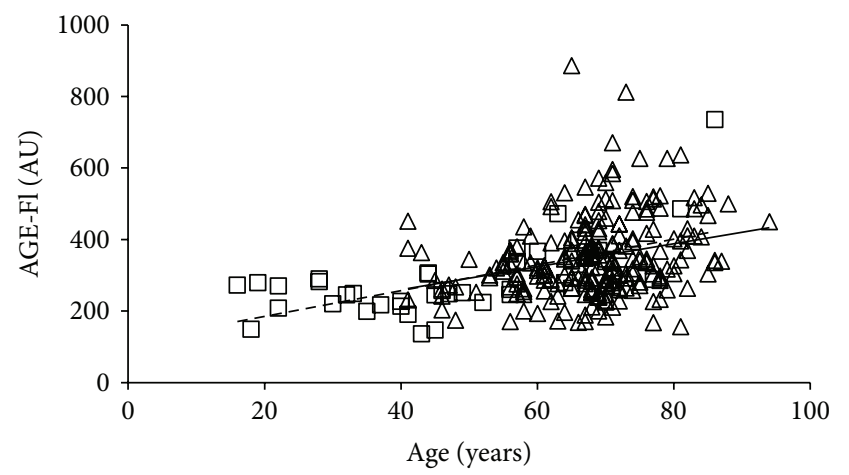

$\square$ DM1

$\triangle \mathrm{DM} 2$

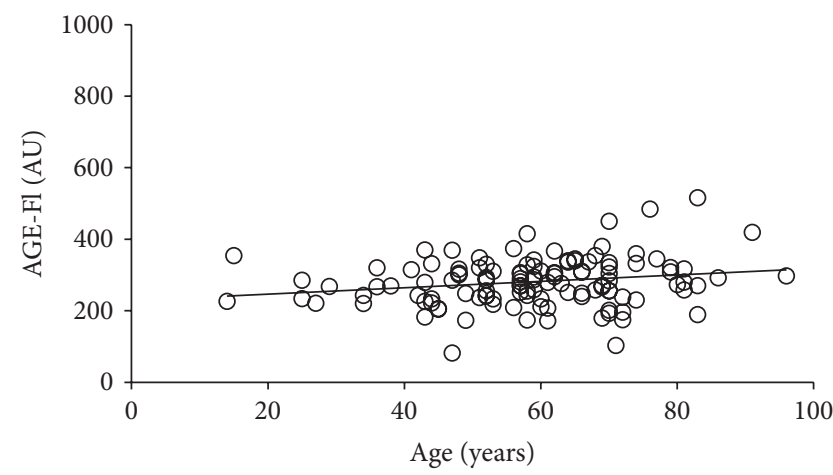

(b)

FIGURE 7: Age-dependent rise in AGE-specific fluorescence of plasma (AGE-Fl) in type 1 and type 2 diabetics (a) and controls (b). DM1: type 1 diabetes mellitus; DM2: type 2 diabetes mellitus; dotted line represents a regression in cohort of type 1 diabetics; solid line represents a regression in cohort of type 2 diabetics; AU: arbitrary units.

In type 1 diabetics multivariate analysis (with age, BMI, eGFR, HbAlc, hsCRP, SAF, CML, sRAGE, sVAP-1, and duration of diabetes entered as independent variables) selected only sVAP-1 (corrected model $P=0.005, R^{2}: 78 \% ; P_{\text {sVAP- } 1}=$ $0.028, \beta=-0.51, \mathrm{SE}=0.19$ ) as a significant independent contributor to AGE-Fl. In type 2 diabetic subjects eGFR was selected as an independent significant contributor to AGEFl (corrected model $P<0.001, R^{2}: 38 \% ; P_{\mathrm{eGFR}}<0.001$, $\beta=-0.006, \mathrm{SE}=0.001)$.

In a similar setting for SAF levels GLM selected age $\left(P_{\text {age }}=0.019, \beta=0.90, \mathrm{SE}=0.31\right)$, sVAP-1 $(P=0.047$, $\beta=0.99, \mathrm{SE}=0.41)$, and sRAGE levels $(P=0.001, \beta=$ -1.13 , SE $=0.20$; corrected model $\left.P=0.006, R^{2}: 84 \%\right)$ as significant associated factors of type 1 diabetics. In type 2 diabetic subjects age $(P=0.006, \beta=1.01, \mathrm{SE}=0.36)$,
eGFR $(P=0.022, \beta=-0.005, \mathrm{SE}=0.002)$, sRAGE levels $(P=0.016, \beta=-0.23, \mathrm{SE}=0.09)$, sVAP-1 $(P=0.014$, $\beta=0.27, \mathrm{SE}=0.11)$, and $\mathrm{CML}(P=0.050, \beta=-0.21, \mathrm{SE}=$ $0.11)$ appeared to be associated independently with SAF levels (corrected model $P<0.001, R^{2}: 37 \%$ ).

In comparison with the diabetics, the age-dependent rise in SAF ( $y=0.018 \times$ age $+1.28, r=0.520, P<0.001)$ and AGEassociated fluorescence of plasma $(y=0.9 \times$ age $+228, r=$ $0.202, P=0.028$ ) was much slower in the controls (Figures $7(\mathrm{~b})$ and $8(\mathrm{~b}))$.

GLM did not select any independent variable association independently and significantly either to AGE-Fl or to SAF in the controls.

The correction for $25(\mathrm{OH}) \mathrm{D}$ did not change the results nor was $25(\mathrm{OH}) \mathrm{D}$ selected as significant contributor if forced into either model. 


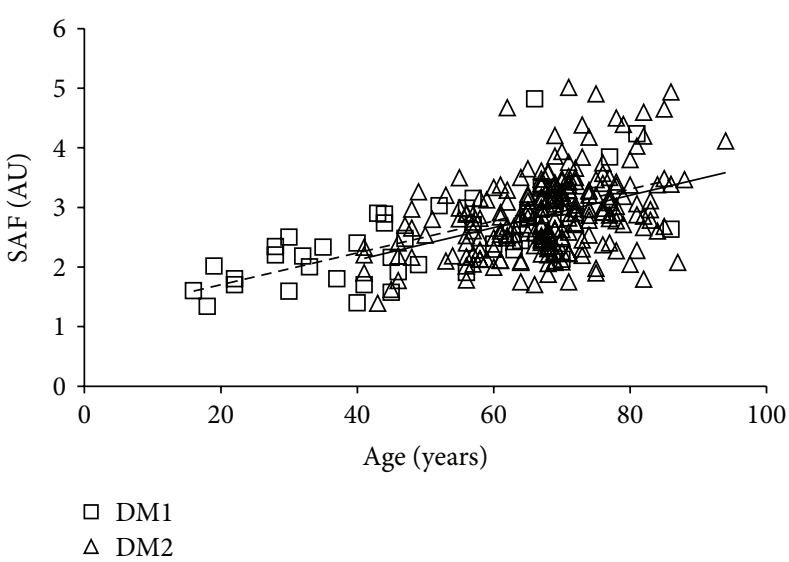

(a)

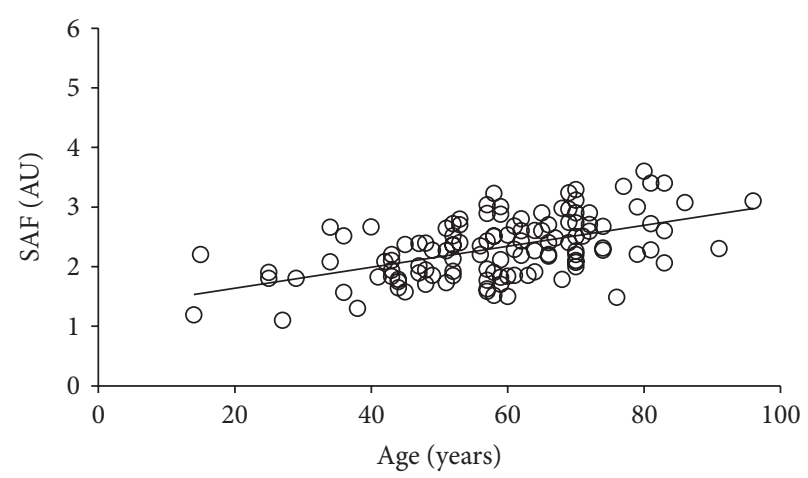

(b)

FIGURE 8: Age-dependent rise in skin autofluorescence (SAF) in controls (a) and type 1 and type 2 diabetics (b). DM1: type 1 diabetes mellitus; DM2: type 2 diabetes mellitus; dotted line represents a regression in cohort of type 1 diabetics; solid line represents a regression in cohort of type 2 diabetics; $\mathrm{AU}$ : arbitrary units.

\section{Discussion}

This is one of the few studies examining in diabetic subjects the relationship between vitamin $\mathrm{D}$ status and AGE accumulation in plasma and skin as well as the AGEassociated biomarkers of microinflammation and oxidative stress. Surprisingly we found no association between vitamin D status and SAF or plasma AGE-Fl. Among the markers of microinflammation/oxidative stress an inverse link between vitamin D and sVAP-1 in the type 2 diabetics could be shown.

4.1. Vitamin D Status. In our study the controls presented mean vitamin $\mathrm{D}$ levels within the lower range of vitamin $\mathrm{D}$ insufficiency and averaging $22.3 \mathrm{ng} / \mathrm{mL}$. This finding corresponds to concentrations reported for the Central European general population (17-to-33 $\mathrm{ng} / \mathrm{mL}$ in mean) from cities in similar latitude as Würzburg (reviewed in [51]). They are higher than those reported for a large cohort of orthopaedic patients in Germany $(18.8 \mathrm{ng} / \mathrm{mL}$ in mean in summer and $16.1 \mathrm{ng} / \mathrm{mL}$ in winter) [52].

In our diabetic subjects the prevalence of hypovitaminosis D was of the same degree as in the controls. In other studies the prevalence of low vitamin D levels was higher in diabetics and individuals with prediabetes compared to nondiabetic controls [53-56]. Consequently a low vitamin $\mathrm{D}$ status was assumed to be involved in the development and also progression of type 2 diabetes. This hypothesis was supported by various experimental and clinical studies which showed an enhanced insulin resistance and/or an impaired secretion of insulin in the pancreatic beta cells in the presence of hypovitaminosis D $[57,58]$. In line with the Tromso study [59] and Zoppini et al. [60], we found in our diabetics an inverse relationship between vitamin D and the HbAlc concentrations. However, this is not a causal relationship since in a meta-analysis of numerous studies vitamin D supplementation was without effect on the disturbed glucose homeostasis [61]. Furthermore in a recent genetic study no proof for a relationship between vitamin $\mathrm{D}$ deficiency and diabetes was found [62].
4.2. Vitamin D Status and BMI. We did not reveal a significant association between vitamin D levels and BMI, in either diabetics or nondiabetic controls; however, multivariate analysis suggested that a higher BMI might be inversely associated with vitamin $\mathrm{D}$ status in nondiabetics. Cholecalciferol is the dominant metabolite and distributed in adipose tissue [63]. Its accumulation in fat cells probably results from its trapping. There is a significant positive association between $25(\mathrm{OH}) \mathrm{D}$ concentration in subcutaneous white adipose tissue and serum [64]. A meta-analysis of 21 studies reported that each unit of increase in BMI $\left(\mathrm{kg} / \mathrm{m}^{2}\right)$ associates with $1.15 \%$ lower plasma concentrations of $25(\mathrm{OH}) \mathrm{D}$ [65]. Further data suggest that reduction of weight and consequently of fat in overweight and obese subjects is not associated with significant changes in white adipose tissue or circulating vitamin $\mathrm{D}_{3}$ levels [64].

4.3. Advanced Glycation End Products. In our controls the age-dependent rise of SAF levels corresponded well with those reported for the general Dutch population [66]. As expected, in our diabetics, the age-dependent rise of SAF was much steeper than in the nondiabetic controls. These data correspond well with studies from Netherlands [67, 68] and from the Czech Republic [69]. In contrast, a large Australian study reported only a tendency towards higher SAF values [15]. The reasons are not clear, but differences in the characteristics of the controls (such as age or presence of comorbidities) and of the diabetics (duration, treatment modalities, and presence of complications and comorbidities) might be important.

Interestingly in our type 1 and type 2 diabetics the agedependent rise of SAF was of the same magnitude and the SAF levels were directly related to duration of the disease (similar between both diabetic groups). No relationships were found to haemoglobin Alc. Also plasma Fl-AGE showed an age-dependent rise in our controls and the diabetics which is in accordance with data of Kalousová et al. [70]. 
4.4. Missing Interactions of Vitamin D and Advanced Glycation End Products. Since in vitro and animal studies showed that vitamin D application lowers the toxic effects of AGEs and decreases their formation $[48,49]$, we were particularly interested in potential relationships between both factors. We expected that low levels of vitamin D could be associated with an enhanced AGE formation, while, in the presence of sufficient vitamin D, lower concentrations of AGEs should occur. Surprisingly, we did not found any link between vitamin $\mathrm{D}$ and SAF.

Also plasma Fl-AGE and vitamin D levels were not interrelated. However, multivariate analysis using the OPLSDA model suggested that vitamin $\mathrm{D}_{3}$ deficient subjects tend to present lower AGE-associated fluorescence of plasma, regardless of presence or absence of diabetes. In a study in elderly type 2 diabetics no relationship between vitamin $\mathrm{D}_{3}$ levels and plasma concentration of Fl-AGEs was found [55].

The missing link between SAF and vitamin D also rules out the possibility that the cutaneous AGE accumulation hinders the photoconversion of the provitamin $\mathrm{D}$ into vitamin D. In line with this assumption, repeated UVB radiation in hemodialysis patients was associated with a marked increase of vitamin $\mathrm{D}_{3}$ status despite the high levels of skin AGEs in these patients [71].

4.5. Markers of Inflammation and Oxidative Stress. In the whole cohort of the diabetics the plasma levels of hs-CRP and sVAP-1 were significantly elevated. Unexpectedly, this rise was on the account of the type 2 diabetics, while in type 1 diabetics these markers of the inflammatory pathway were not enhanced. This observation is surprising with regard to the identical elevation of the HbAlc levels in both groups. This disparate pathobiochemistry may be explained by the different aetiology and pathophysiology of both diabetic states as also proposed by Kalousová et al. [70]. Type 1 diabetes mellitus is an immunological disease and characterized by dysfunction of the pancreatic $\beta$-cells. It usually develops in younger age in the absence of obesity, insulin resistance, and hypertension. In contrast, type 2 diabetes mellitus represents an insulin-resistant state and manifests in the majority of patients with a metabolic syndrome in the middle or higher age. Central obesity favors the development of dyslipidemia, microinflammation, and oxidative stress $[72,73]$ as well as hypertension [74]. Correspondingly, our type 2 diabetics were older, presented 1.4-fold higher incidence of hypertension and a higher BMI as compared to type 1 diabetics.

The sVAP-1 levels were elevated in hypovitaminosis D and showed an independent inverse association with the $25(\mathrm{OH}) \mathrm{D}$ concentrations in both diabetic cohorts. The augmented sVAP-1 levels might reflect involvement of oxidative stress and/or microinflammation in part due to AGE accumulation. sVAP-1, known also as semicarbazide-sensitive amine oxidase (SSAO, EC 1.4.3.21), represents a molecule with a dual action: it favors lymphocyte adhesion to damaged endothelium and plays a role in the monoamine detoxification metabolizing primary amines into corresponding aldehydes, generating $\mathrm{H}_{2} \mathrm{O}_{2}$ and ammonia [75]. Increased SSAO activity in diabetes may result from enhanced SSAO substrates such as methylamine or aminoacetone.
It remains unclear whether the association of low vitamin $\mathrm{D}_{3}$ and elevated sVAP-1 levels is a coincidence or causally related to proinflammatory consequences of hypovitaminosis D. In the latter case an augmented sVAP-1 could result from release from endothelial cells (following the shedding by metalloproteinases) or induction of the VAP-1/SSAO gene expression. In diabetes the conversion of aminoacetone by SSAO to methylglyoxal is increased and has been claimed to be related to induction of insulin resistance and development of diabetic complications [76-78]. In humans the hyperglycemia-induced rise of circulating sVAP-1 levels directly correlates with the plasma AGE concentration [79]. Moreover, sVAP-1 is associated with subclinical atherosclerotic manifestations and an increased risk of cardiovascular events and mortality rate [80].

Since both AGE accumulation [81] and vitamin D deficiency [82] may be associated with impaired muscle strength we performed the hand-grip test in the controls and diabetics. In our study we did not observe an association between elevated AGEs and impaired grip strength in control group or in diabetics. However, in contrast to the controls, in diabetic patients (type 1 and type 2) with hypovitaminosis D (insufficient and deficient vitamin D levels), we noticed impaired grip strength.

In our study, potential confounding factors to the toxic effects of AGEs and hypovitaminosis D have to be considered. First of all the impact of tight blood glucose control has to be mentioned. The mean HbAlc level of 7.1 demonstrates that in most patients glycemia was well controlled. All hypertensive patients including the nondiabetic controls were treated with either ACE-inhibitors or angiotensin II receptor blockers. These compounds exert anti-inflammatory, antioxidative, and anti-AGE forming effects as demonstrated in in vitro studies, animal models, and clinical trials [83-85]. Furthermore the frequently prescribed statins were shown to reduce microinflammation and oxidative stress [86-88] as well as the formation of AGEs [89], in part by increasing soluble RAGE [90]. Interestingly certain statins may enhance the formation of vitamin $\mathrm{D}_{3}$ [91] which could explain the missing difference of vitamin $\mathrm{D}$ levels in our nondiabetic and diabetic cohorts. A very potent drug with anti-inflammatory actions is metformin which was administered to most of the type 2 diabetic patients $[92,93]$ except in patients with creatinine clearance less than $60 \mathrm{~mL} / \mathrm{min}$.

Taken together, in our diabetic patients, the vitamin $\mathrm{D}_{3}$ deficiency was not unequivocally and expressively associated with markers of microinflammation and oxidative stress. This could suggest that the postulated anti-inflammatory action of vitamin D is rather limited or may even be absent under certain conditions. In fact in various inflammatory states the vitamin deficiency was not the cause, but a consequence of the disease (elective knee arthroplasty [94], critically ill patients [95]). Correspondingly in various controlled studies (in contrast to observational investigations), supplementation with vitamin $\mathrm{D}$ did not improve the microinflammation and oxidative stress [62]. However, in patients with chronic kidney disease, hypovitaminosis $\mathrm{D}$ is frequently associated with secondary hyperparathyroidism which is suppressed by vitamin D supplementation [96]. Although still needing 
placebo-controlled studies, vitamin D supplementations in elderly people "seemed to decrease mortality" [97].

Summarizing, our cross-sectional study suggests that in diabetic subjects hypovitaminosis $\mathrm{D}$ is not associated with enhanced AGE accumulation and sufficient vitamin D levels are not linked with a lower AGE accumulation. Moreover, we conclude that an excessive rise of skin AGEs does not interfere with dermal vitamin $\mathrm{D}_{3}$ formation. The relationships between vitamin $\mathrm{D}_{3}$ deficiency and markers of inflammation showed a different pattern. We found higher levels of s-VAP 1 in hypovitaminosis D, but hs-CRP levels were unchanged. These data suggest that hypovitaminosis D seems to be of limited importance for development of microinflammation and accumulation of AGEs. With regard to equivocal results of our cross-sectional study, controlled longitudinal studies focusing on the effects of vitamin D supplementation on skin and plasma AGE and markers of microinflammation/oxidative stress are needed to elucidate a potential relationship between vitamin $\mathrm{D}$ status and AGE accumulation and their interaction in potentiating of toxic effects.

\section{Abbreviations}

25(OH)D: 25-Hydroxyvitamin D (calcidiol)

AGEs: $\quad$ Advanced glycation end products

AGE-Fl: Advanced glycation end products associated fluorescence of plasma

ANOVA: Analysis of variance

CHD: $\quad$ Coronary heart disease

BMI: $\quad$ Body mass index

CKD: $\quad$ Chronic kidney disease

CML: $\quad \mathrm{N}^{\varepsilon}$-Carboxymethyllysine

GLM: $\quad$ General Linear Model

HbAlc: Haemoglobin Alc

eGFR: Estimated glomerular filtration rate

hs-CRP: High sensitive C-reactive protein

HT: Hypertension

Ln: Logarithm

NF- $\kappa$ B: $\quad$ Nuclear factor kappa-B

NO: $\quad$ Nitric oxide

OPLS-DA: Orthogonal projections to latent structures discriminant analysis

PAD: $\quad$ Peripheral artery disease

RAGE: Receptor for advanced glycation end products

sRAGE: Soluble receptor for advanced glycation end products

SAF: $\quad$ Skin advanced glycation end products associated autofluorescence

sVAP-1: $\quad$ Soluble vascular adhesion protein-1

TGF- $\beta-1$ : Transforming growth factor- $\beta-1$

VIP: Variables importance for the projection.

\section{Conflict of Interests}

Dr. F. Stäb is an employee of Beiersdorf AG, Hamburg, Germany. Other authors declare no competing interests.

\section{Acknowledgments}

The authors thank all volunteers consenting to participate and Dr. Karl-Heinz Antonin, Würzburg, Germany, for his vital support in writing the paper. This study was in part financially supported by Beiersdorf AG, Hamburg, Germany.

\section{References}

[1] M. Brownlee, "Lilly lecture 1993. Glycation and diabetic complications," Diabetes, vol. 43, no. 6, pp. 836-841, 1994.

[2] T. Miyata, Y. Wada, Z. Cai et al., "Implication of an increased oxidative stress in the formation of advanced glycation end products in patients with end-stage renal failure," Kidney International, vol. 51, no. 4, pp. 1170-1181, 1997.

[3] A. Gugliucci and M. Bendayan, "Renal fate of circulating advanced glycated end products (AGE): evidence for reabsorption and catabolism of AGE-peptides by renal proximal tubular cells," Diabetologia, vol. 39, no. 2, pp. 149-160, 1996.

[4] J. Uribarri, S. Woodruff, S. Goodman et al., "Advanced glycation end products in foods and a practical guide to their reduction in the diet," Journal of the American Dietetic Association, vol. 110, no. 6, pp. 911-916, 2010.

[5] K. Šebeková, K. S. Klenovics, P. Boor et al., "Behaviour and hormonal status in healthy rats on a diet rich in Maillard reaction products with or without solvent extractable aroma compounds," Physiology and Behavior, vol. 105, no. 3, pp. 693701, 2012.

[6] C. Cerami, H. Founds, I. Nicholl et al., "Tobacco smoke is a source of toxic reactive glycation products," Proceedings of the National Academy of Sciences of the United States of America, vol. 94, no. 25, pp. 13915-13920, 1997.

[7] S. Zieman and D. Kass, "Advanced glycation end product cross-linking: pathophysiologic role and therapeutic target in cardiovascular disease," Congestive Heart Failure, vol. 10, no. 3, pp. 144-151, 2004.

[8] J. M. Haus, J. A. Carrithers, S. W. Trappe, and T. A. Trappe, "Collagen, cross-linking, and advanced glycation end products in aging human skeletal muscle," Journal of Applied Physiology, vol. 103, no. 6, pp. 2068-2076, 2007.

[9] P. J. Thornalley, "Cell activation by glycated proteins. AGE receptors, receptor recognition factors and functional classification of AGEs," Cellular and Molecular Biology (Noisy-le-Grand, France), vol. 44, no. 7, pp. 1013-1023, 1998.

[10] G. Rashid, S. Benchetrit, D. Fishman, and J. Bernheim, "Effect of advanced glycation end-products on gene expression and synthesis of TNF- $\alpha$ and endothelial nitric oxide synthase by endothelial cells," Kidney International, vol. 66, no. 3, pp. 10991106, 2004.

[11] N. Ohgami, A. Miyazaki, M. Sakai, A. Kuniyasu, H. Nakayama, and S. Horiuchi, "Advanced glycation end products (AGE) inhibit scavenger receptor class B type I-mediated reverse cholesterol transport: a new crossroad of AGE to cholesterol metabolism," Journal of Atherosclerosis and Thrombosis, vol. 10, no. 1, pp. 1-6, 2003.

[12] N. Schupp, R. Schinzel, A. Heidland, and H. Stopper, "Genotoxicity of advanced glycation end products: involvement of oxidative stress and of angiotensin II type 1 receptors," Annals of the New York Academy of Sciences, vol. 1043, pp. 685-695, 2005.

[13] K. Šebeková, Z. Wagner, N. Schupp, and P. Boor, "Genomic damage and malignancy in end-stage renal failure: do advanced 
glycation end products contribute?" Kidney and Blood Pressure Research, vol. 30, no. 1, pp. 56-66, 2007.

[14] R. Bucala and A. Cerami, "Advanced glycosylation: chemistry, biology, and implications for diabetes and aging," Advances in Pharmacology, vol. 23, pp. 1-34, 1992.

[15] C. Moran, G. Münch, J. M. Forbes et al., "Type 2 diabetes, skin autofluorescence, and brain atrophy," Diabetes, vol. 64, no. 1, pp. 279-283, 2014.

[16] M. T. Coughlan, F. Y. T. Yap, D. C. K. Tong et al., "Advanced glycation end products are direct modulators of $\beta$-cell function," Diabetes, vol. 60, no. 10, pp. 2523-2532, 2011.

[17] S. J. Hunter, A. C. Boyd, F. P. M. O’Harte et al., "Demonstration of glycated insulin in human diabetic plasma and decreased biological activity assessed by euglycemic-hyperinsulinemic clamp technique in humans," Diabetes, vol. 52, no. 2, pp. 492498, 2003.

[18] J. W. L. Hartog, A. A. Voors, S. J. L. Bakker, A. J. Smit, and D. J. van Veldhuisen, "Advanced glycation end-products (AGEs) and heart failure: pathophysiology and clinical implications," European Journal of Heart Failure, vol. 9, no. 12, pp. 1146-1155, 2007.

[19] A. Lapolla, F. Piarulli, G. Sartore et al., "Advanced glycation end products and antioxidant status in type 2 diabetic patients with and without peripheral artery disease," Diabetes Care, vol. 30, no. 3, pp. 670-676, 2007.

[20] M. L. Melamed, E. D. Michos, W. Post, and B. Astor, "25hydroxyvitamin D levels and the risk of mortality in the general population," Archives of Internal Medicine, vol. 168, no. 15, pp. 1629-1637, 2008.

[21] B. K. Kilhovd, A. Juutilainen, S. Lehto et al., "Increased serum levels of advanced glycation endproducts predict total, cardiovascular and coronary mortality in women with type 2 diabetes: a population-based 18 year follow-up study," Diabetologia, vol. 50, no. 7, pp. 1409-1417, 2007.

[22] Z. Wagner, M. Molnár, G. A. Molnár et al., "Serum carboxymethyllysine predicts mortality in hemodialysis patients," American Journal of Kidney Diseases, vol. 47, no. 2, pp. 294-300, 2006.

[23] A. Raucci, S. Cugusi, A. Antonelli et al., "A soluble form of the receptor for advanced glycation endproducts (RAGE) is produced by proteolytic cleavage of the membrane-bound form by the sheddase a disintegrin and metalloprotease 10 (ADAM10)," The FASEB Journal, vol. 22, no. 10, pp. 37163727, 2008.

[24] R. Meerwaldt, R. Graaf, P. H. N. Oomen et al., "Simple noninvasive assessment of advanced glycation endproduct accumulation," Diabetologia, vol. 47, no. 7, pp. 1324-1330, 2004.

[25] R. Meerwaldt, C. J. Zeebregts, G. Navis, J.-L. Hillebrands, J. D. Lefrandt, and A. J. Smit, "Accumulation of advanced glycation end products and chronic complications in ESRD treated by dialysis," The American Journal of Kidney Diseases, vol. 53, no. 1, pp. 138-150, 2009.

[26] D. J. Mulder, T. van de Water, H. L. Lutgers et al., "Skin autofluorescence, a novel marker for glycemic and oxidative stress-derived advanced glycation endproducts: an overview of current clinical studies, evidence, and limitations," Diabetes Technology and Therapeutics, vol. 8, no. 5, pp. 523-535, 2006.

[27] N. J. Mcintyre, R. J. Fluck, C. W. Mcintyre, and M. W. Taal, "Skin autofluorescence and the association with renal and cardiovascular risk factors in chronic kidney disease stage 3," Clinical Journal of the American Society of Nephrology, vol. 6, no. 10, pp. 2356-2363, 2011.
[28] M. F. Holick, "Vitamin D deficiency," TheNew England Journal of Medicine, vol. 357, no. 3, pp. 266-281, 2007.

[29] T. J. Wang, M. J. Pencina, S. L. Booth et al., "Vitamin D deficiency and risk of cardiovascular disease," Circulation, vol. 117, no. 4, pp. 503-511, 2008.

[30] Y. C. Li, J. Kong, M. Wei, Z.-F. Chen, S. Q. Liu, and L.-P. Cao, "1,25-Dihydroxyvitamin $\mathrm{D}_{3}$ is a negative endocrine regulator of the renin-angiotensin system," The Journal of Clinical Investigation, vol. 110, no. 2, pp. 229-238, 2002.

[31] R. Scragg, M. Sowers, and C. Bell, "Serum 25-hydroxyvitamin $D$, ethnicity, and blood pressure in the Third National Health and Nutrition Examination Survey," The American Journal of Hypertension, vol. 20, no. 7, pp. 713-719, 2007.

[32] S. Pilz, A. Tomaschitz, E. Ritz, and T. R. Pieber, "Vitamin D status and arterial hypertension: a systematic review," Nature Reviews Cardiology, vol. 6, no. 10, pp. 621-630, 2009.

[33] I. Al Mheid, R. Patel, J. Murrow et al., "Vitamin D status is associated with arterial stiffness and vascular dysfunction in healthy humans," Journal of the American College of Cardiology, vol. 58, no. 2, pp. 186-192, 2011.

[34] K. E. Watson, M. L. Abrolat, L. L. Malone et al., "Active serum vitamin D levels are inversely correlated with coronary calcification," Circulation, vol. 96, no. 6, pp. 1755-1760, 1997.

[35] I. H. de Boer, B. Kestenbaum, A. B. Shoben, E. D. Michos, M. J. Sarnak, and D. S. Siscovick, "25-Hydroxyvitamin D levels inversely associate with risk for developing coronary artery calcification," Journal of the American Society of Nephrology, vol. 20, no. 8, pp. 1805-1812, 2009.

[36] S. Pilz, H. Dobnig, J. E. Fischer et al., "Low vitamin D levels predict stroke in patients referred to coronary angiography," Stroke, vol. 39, no. 9, pp. 2611-2613, 2008.

[37] A. F. Gombart, N. Borregaard, and H. P. Koeffler, "Human cathelicidin antimicrobial peptide (CAMP) gene is a direct target of the vitamin D receptor and is strongly up-regulated in myeloid cells by 1,25 -dihydroxyvitamin $\mathrm{D}_{3}$," The FASEB Journal, vol. 19, no. 9, pp. 1067-1077, 2005.

[38] C. Balion, L. E. Griffith, L. Strifler et al., "Vitamin D, cognition, and dementia: a systematic review and meta-analysis," Neurology, vol. 79, no. 13, pp. 1397-1405, 2012.

[39] C. Mattila, P. Knekt, S. Männistö et al., "Serum 25hydroxyvitamin D concentration and subsequent risk of type 2 diabetes," Diabetes Care, vol. 30, no. 10, pp. 2569-2570, 2007.

[40] A. W. Norman, B. J. Frankel, A. M. Heldt, and G. M. Grodsky, "Vitamin D deficiency inhibits pancreatic secretion of insulin," Science, vol. 209, no. 4458, pp. 823-825, 1980.

[41] J. Guo, Z. Xiao, X. Xue et al., "25-hydroxyvitamin D is closely related with the function of the pancreatic islet $\beta$ cells," Pakistan Journal of Medical Sciences, vol. 29, no. 3, pp. 809-813, 2013.

[42] C. V. Harinarayan, S. Arvind, S. Joshi, K. Thennarasu, V. Vedavyas, and A. Baindur, "Improvement in pancreatic $\beta$-cell function with vitamin $D$ and calcium supplementation in vitamin D deficient non-diabetic subjects," Endocrine Practice, vol. 20, no. 2, pp. 129-138, 2014.

[43] A. G. Pittas, J. Lau, F. B. Hu, and B. Dawson-Hughes, "The role of vitamin $\mathrm{D}$ and calcium in type 2 diabetes. A systematic review and meta-analysis," Journal of Clinical Endocrinology and Metabolism, vol. 92, no. 6, pp. 2017-2029, 2007.

[44] D. P. Choi, S. M. Oh, J. M. Lee et al., "Serum 25-hydroxyvitamin D and insulin resistance in apparently healthy adolescents," PLoS ONE, vol. 9, Article ID e103108, 2014. 
[45] A. Badawi, S. Sayegh, E. Sadoun, M. Al-Thani, P. Arora, and P. S. Haddad, "Relationship between insulin resistance and plasma vitamin D in adults," Diabetes, Metabolic Syndrome and Obesity: Targets and Therapy, vol. 7, pp. 297-303, 2014.

[46] C. Joergensen, P. Hovind, A. Schmedes, H.-H. Parving, and P. Rossing, "Vitamin D levels, microvascular complications, and mortality in type 1 diabetes," Diabetes Care, vol. 34, no. 5, pp. 1081-1085, 2011.

[47] C. M. Girgis, R. J. Clifton-Bligh, M. W. Hamrick, M. F. Holick, and J. E. Gunton, "The roles of vitamin D in skeletal muscle: form, function, and metabolism," Endocrine Reviews, vol. 34, no. 1, pp. 33-83, 2013.

[48] Y. Talmor, E. Golan, S. Benchetrit et al., "Calcitriol blunts the deleterious impact of advanced glycation end products on endothelial cells," American Journal of Physiology: Renal Physiology, vol. 294, no. 5, pp. F1059-F1064, 2008.

[49] E. Salum, J. Kals, P. Kampus et al., "Vitamin D reduces deposition of advanced glycation end-products in the aortic wall and systemic oxidative stress in diabetic rats," Diabetes Research and Clinical Practice, vol. 100, no. 2, pp. 243-249, 2013.

[50] G. Münch, R. Keis, A. Wessels et al., "Determination of advanced glycation end products in serum by fluorescence spectroscopy and competitive ELISA1)," European Journal of Clinical Chemistry and Clinical Biochemistry, vol. 35, no. 9, pp. 669-677, 1997.

[51] P. Pludowski, W. B. Grant, H. P. Bhattoa et al., "Vitamin D status in central Europe," International Journal of Endocrinology, vol. 2014, Article ID 589587, 12 pages, 2014.

[52] G. S. Maier, P. Jakobs, K. E. Roth, A. A. Kurth, and U. Maus, "Is there an epidemic vitamin D deficiency in German orthopaedic patients?" Clinical Orthopaedics and Related Research, vol. 471, no. 9, pp. 3029-3035, 2013.

[53] J. Mitri, M. D. Muraru, and A. G. Pittas, "Vitamin D and type 2 diabetes: a systematic review," European Journal of Clinical Nutrition, vol. 65, no. 9, pp. 1005-1015, 2011.

[54] N. G. Forouhi, Z. Ye, A. P. Rickard et al., "Circulating 25hydroxyvitamin $\mathrm{D}$ concentration and the risk of type 2 diabetes: results from the European Prospective Investigation into Cancer (EPIC)-Norfolk cohort and updated meta-analysis of Prospective studies," Diabetologia, vol. 55, no. 8, pp. 2173-2182, 2012.

[55] D. Gradinaru, C. Borsa, C. Ionescu, D. Margina, G. I. Prada, and E. Jansen, "Vitamin D status and oxidative stress markers in the elderly with impaired fasting glucose and type 2 diabetes mellitus," Aging Clinical and Experimental Research, vol. 24, no. 6, pp. 595-602, 2012.

[56] Y. Song, L. Wang, A. G. Pittas et al., "Blood 25-hydroxy vitamin D levels and incident type 2 diabetes: a meta-analysis of prospective studies," Diabetes Care, vol. 36, no. 5, pp. 1422-1428, 2013.

[57] K. C. Chiu, A. Chu, V. L. W. Go, and M. F. Saad, "Hypovitaminosis $\mathrm{D}$ is associated with insulin resistance and $\beta$ cell dysfunction," American Journal of Clinical Nutrition, vol. 79, no. 5, pp. 820-825, 2004.

[58] X. Palomer, J. M. González-Clemente, F. Blanco-Vaca, and D. Mauricio, "Role of vitamin D in the pathogenesis of type 2 diabetes mellitus," Diabetes, Obesity and Metabolism, vol. 10, no. 3, pp. 185-197, 2008.

[59] M. S. Hutchinson, Y. Figenschau, I. Njølstad, H. Schirmer, and R. Jorde, "Serum 25-hydroxyvitamin D levels are inversely associated with glycated haemoglobin $\left(\mathrm{HbA}_{1 c}\right)$. The Tromsø Study,"
Scandinavian Journal of Clinical and Laboratory Investigation, vol. 71, no. 5, pp. 399-406, 2011.

[60] G. Zoppini, A. Galletti, G. Targher et al., "Glycated haemoglobin is inversely related to serum vitamin D levels in type 2 diabetic patients," PLoS ONE, vol. 8, no. 12, Article ID e82733, 2013.

[61] J. C. Seida, J. Mitri, I. N. Colmers et al., "Effect of vitamin d3 supplementation on improving glucose homeostasis and preventing diabetes: a systematic review and meta-analysis," The Journal of Clinical Endocrinology \& Metabolism, vol. 99, no. 10, pp. 3551-3560, 2014.

[62] P. Autier, M. Boniol, C. Pizot, and P. Mullie, "Vitamin D status and ill health: a systematic review," The Lancet Diabetes and Endocrinology, vol. 2, no. 1, pp. 76-89, 2014.

[63] E. B. Mawer, J. Backhouse, C. A. Holman, G. A. Lumb, and S. W. Stanbury, "The distribution and storage of vitamin D and its metabolites in human tissues," Clinical Science, vol. 43, no. 3, pp. 413-431, 1972.

[64] B. D. Piccolo, G. Dolnikowski, E. Seyoum et al., "Association between subcutaneous white adipose tissue and serum 25hydroxyvitamin D in overweight and obese adults," Nutrients, vol. 5, no. 9, pp. 3352-3366, 2013.

[65] K. S. Vimaleswaran, A. Cavadino, D. J. Berry et al., "Genetic association analysis of vitamin D pathway with obesity traits," International Journal of Obesity, vol. 37, no. 10, pp. 1399-1406, 2013.

[66] M. Koetsier, H. L. Lutgers, C. de Jonge, T. P. Links, A. J. Smit, and R. Graaff, "Reference values of skin autofluorescence," Diabetes Technology and Therapeutics, vol. 12, no. 5, pp. 399-403, 2010.

[67] R. Meerwaldt, T. P. Links, R. Graaff et al., "Increased accumulation of skin advanced glycation end-products precedes and correlates with clinical manifestation of diabetic neuropathy," Diabetologia, vol. 48, no. 8, pp. 1637-1644, 2005.

[68] E. G. Gerrits, H. L. Lutgers, N. Kleefstra et al., "Skin autofluorescence: a tool to identify type 2 diabetic patients at risk for developing microvascular complications," Diabetes Care, vol. 31, no. 3, pp. 517-521, 2008.

[69] J. Škrha, J. Šoupal, G. Loni Ekali et al., "Skin autofluorescence relates to soluble receptor for advanced glycation end-products and albuminuria in diabetes mellitus," Journal of Diabetes Research, vol. 2013, Article ID 650694, 7 pages, 2013.

[70] M. Kalousová, J. Škrha, and T. Zima, "Advanced glycation endproducts and advanced oxidation protein products in patients with diabetes mellitus," Physiological Research, vol. 51, no. 6, pp. 597-604, 2002.

[71] M. J. Ala-Houhala, K. Vähävihu, T. Hasan et al., "Narrowband ultraviolet B exposure increases serum vitamin D levels in haemodialysis patients," Nephrology Dialysis Transplantation, vol. 27, no. 6, pp. 2435-2440, 2012.

[72] C. N. Lumeng, J. L. Bodzin, and A. R. Saltiel, "Obesity induces a phenotypic switch in adipose tissue macrophage polarization," The Journal of Clinical Investigation, vol. 117, no. 1, pp. 175-184, 2007.

[73] T. Mazzone, "Intensive glucose lowering and cardiovascular disease prevention in diabetes: reconciling the recent clinical trial data," Circulation, vol. 122, no. 21, pp. 2201-2211, 2010.

[74] A. Chandra, I. J. Neeland, J. D. Berry et al., "The relationship of body mass and fat distribution with incident hypertension: observations from the Dallas Heart Study," Journal of the American College of Cardiology, vol. 64, pp. 997-1002, 2014.

[75] Y. Deng and P. H. Yu, "Assessment of the deamination of aminoacetone, an endogenous substrate for semicarbazide-sensitive 
amine oxidase," Analytical Biochemistry, vol. 270, no. 1, pp. 97$102,1999$.

[76] F. Boomsma, A. H. van den Meiracker, S. Winkel et al., "Circulating semicarbazide-sensitive amine oxidase is raised both in Type I (insulin-dependent), in Type II (non-insulin-dependent) diabetes mellitus and even in childhood Type I diabetes at first clinical diagnosis," Diabetologia, vol. 42, no. 2, pp. 233-237, 1999.

[77] C. Nigro, G. A. Raciti, A. Leone et al., "Methylglyoxal impairs endothelial insulin sensitivity both in vitro and in vivo," Diabetologia, vol. 57, pp. 1485-1494, 2014.

[78] F. Fiory, A. Lombardi, C. Miele, J. Giudicelli, F. Beguinot, and E. van Obberghen, "Methylglyoxal impairs insulin signalling and insulin action on glucose-induced insulin secretion in the pancreatic beta cell line INS-1E," Diabetologia, vol. 54, no. 11, pp. 2941-2952, 2011.

[79] H.-Y. Li, M.-S. Lin, J.-N. Wei et al., "Change of serum vascular adhesion protein-1 after glucose loading correlates to carotid intima-medial thickness in non-diabetic subjects," Clinica Chimica Acta, vol. 403, no. 1-2, pp. 97-101, 2009.

[80] K. Aalto, A. S. Havulinna, S. Jalkanen, V. Salomaa, and M. Salmi, "Soluble vascular adhesion protein-1 predicts incident major adverse cardiovascular events and improves reclassification in a finnish prospective cohort study," Circulation: Cardiovascular Genetics, vol. 7, no. 4, pp. 529-535, 2014.

[81] H. Momma, K. Niu, Y. Kobayashi et al., "Skin advanced glycation end product accumulation and muscle strength among adult men," European Journal of Applied Physiology, vol. 111, no. 7, pp. 1545-1552, 2011.

[82] J. C. Gallagher, "Vitamin D deficiency and muscle strength: are they related?" Journal of Clinical Endocrinology and Metabolism, vol. 97, no. 12, pp. 4366-4369, 2012.

[83] J. M. Forbes, M. E. Cooper, V. Thallas et al., "Reduction of the accumulation of advanced glycation end products by ACE inhibition in experimental diabetic nephropathy," Diabetes, vol. 51, pp. 3274-3282, 2002.

[84] M. Nangaku, T. Miyata, T. Sada et al., "Anti-hypertensive agents inhibit in vivo the formation of advanced glycation end products and improve renal damage in a type 2 diabetic nephropathy rat model," Journal of the American Society of Nephrology, vol. 14, no. 5, pp. 1212-1222, 2003.

[85] K. Šebeková, K. Gazdíková, D. Syrová et al., "Effects of ramipril in nondiabetic nephropathy: improved parameters of oxidatives stress and potential modulation of advanced glycation end products," Journal of Human Hypertension, vol. 17, no. 4, pp. 265-270, 2003.

[86] M. A. Albert, E. Danielson, N. Rifai, and P. M. Ridker, "Effect of statin therapy on C-reactive protein levels: the pravastatin inflammation/CRP evaluation (PRINCE): a randomized trial and cohort study," The Journal of the American Medical Association, vol. 286, no. 1, pp. 64-70, 2001.

[87] U. Landmesser, F. Bahlmann, M. Mueller et al., "Simvastatin versus ezetimibe pleiotropic and lipid-lowering effects on endothelial function in humans," Circulation, vol. 111, no. 18, pp. 2356-2363, 2005.

[88] C. Antoniades, C. Bakogiannis, P. Leeson et al., "Rapid, direct effects of statin treatment on arterial redox state and nitric oxide bioavailability in human atherosclerosis via tetrahydrobiopterin-mediated endothelial nitric oxide synthase coupling," Circulation, vol. 124, no. 3, pp. 335-345, 2011.

[89] Y. Jinnouchi, S. Yamagishi, M. Takeuchi et al., "Atorvastatin decreases serum levels of advanced glycation end products
(AGEs) in patients with type 2 diabetes," Clinical and Experimental Medicine, vol. 6, no. 4, pp. 191-193, 2006.

[90] P. Quade-Lyssy, A. M. Kanarek, M. Baiersdörfer, R. Postina, and E. Kojro, "Statins stimulate the production of a soluble form of the receptor for advanced glycation end products," Journal of Lipid Research, vol. 54, no. 11, pp. 3052-3061, 2013.

[91] T. Sathyapalan, J. Shepherd, S. L. Atkin, and E. S. Kilpatrick, "The effect of atorvastatin and simvastatin on vitamin D, oxidative stress and inflammatory marker concentrations in patients with type 2 diabetes: a crossover study," Diabetes, Obesity and Metabolism, vol. 15, no. 8, pp. 767-769, 2013.

[92] C. J. Bailey, "Metformin: effects on micro and macrovascular complications in type 2 diabetes," Cardiovascular Drugs and Therapy, vol. 22, no. 3, pp. 215-224, 2008.

[93] K. Isoda, J. L. Young, A. Zirlik et al., "Metformin inhibits proinflammatory responses and nuclear factor-kappaB in human vascular wall cells," Arteriosclerosis, Thrombosis, and Vascular Biology, vol. 26, no. 3, pp. 611-617, 2006.

[94] D. Reid, B. J. Toole, S. Knox et al., "The relation between acute changes in the systemic inflammatory response and plasma 25-hydroxyvitamin D concentrations after elective knee arthroplasty," American Journal of Clinical Nutrition, vol. 93, no. 5, pp. 1006-1011, 2011.

[95] P. Lee, J. A. Eisman, and J. R. Center, "Vitamin D deficiency in critically ill patients," The New England Journal of Medicine, vol. 360, no. 18, pp. 1912-1914, 2009.

[96] Y.-T. Lee, H.-Y. Ng, C.-C. Kuo et al., "Comparison between calcitriol and calcitriol plus low-dose cinacalcet for the treatment of moderate to severe secondary hyperparathyroidism in chronic dialysis patients," Nutrients, vol. 5, no. 4, pp. 1336-1348, 2013.

[97] G. Bjelakovic, L. L. Gluud, D. Nikolova et al., "Vitamin D supplementation for prevention of mortality in adults," Cochrane Database of Systematic Reviews, no. 7, Article ID CD007470, 2014. 


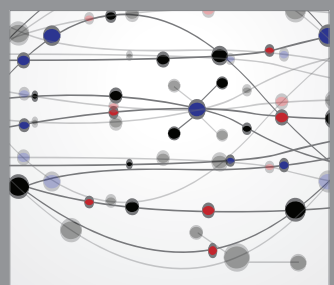

The Scientific World Journal
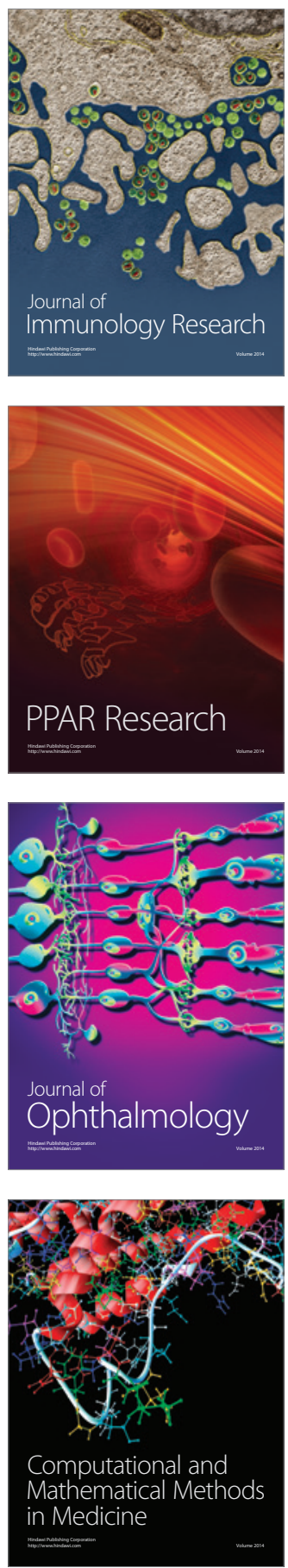

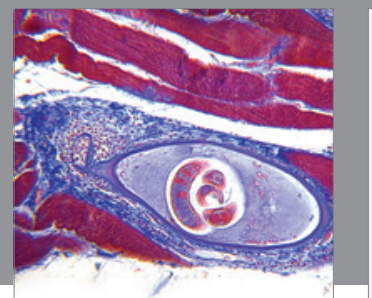

Gastroenterology

Research and Practice
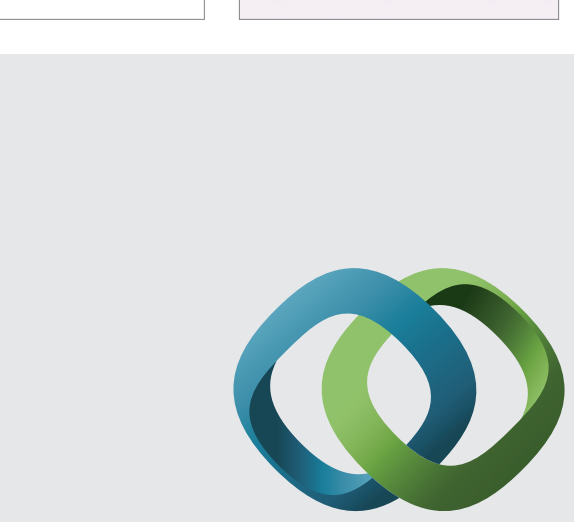

\section{Hindawi}

Submit your manuscripts at

http://www.hindawi.com
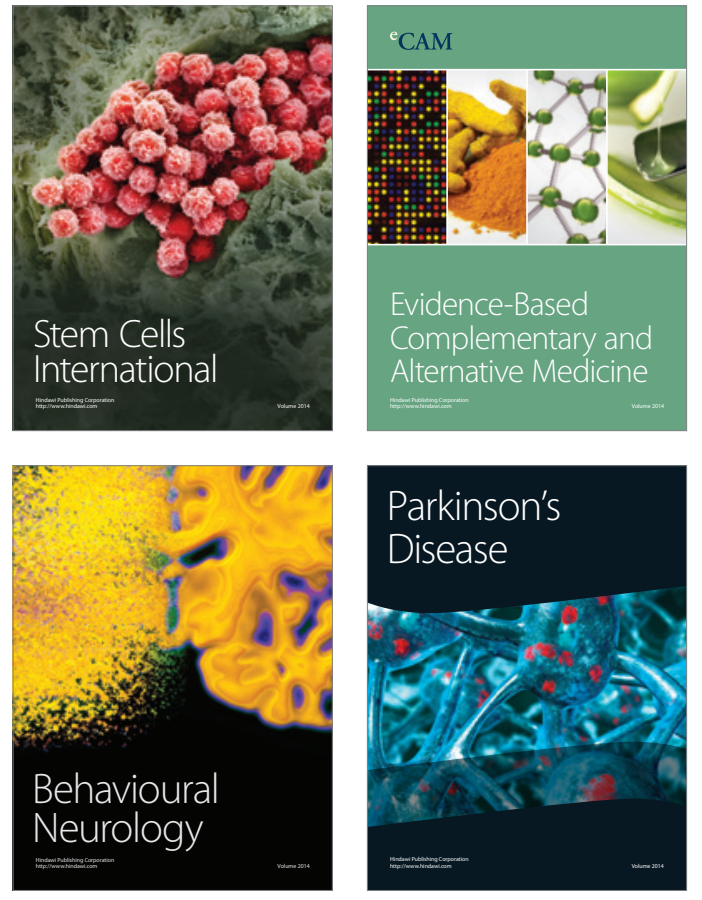
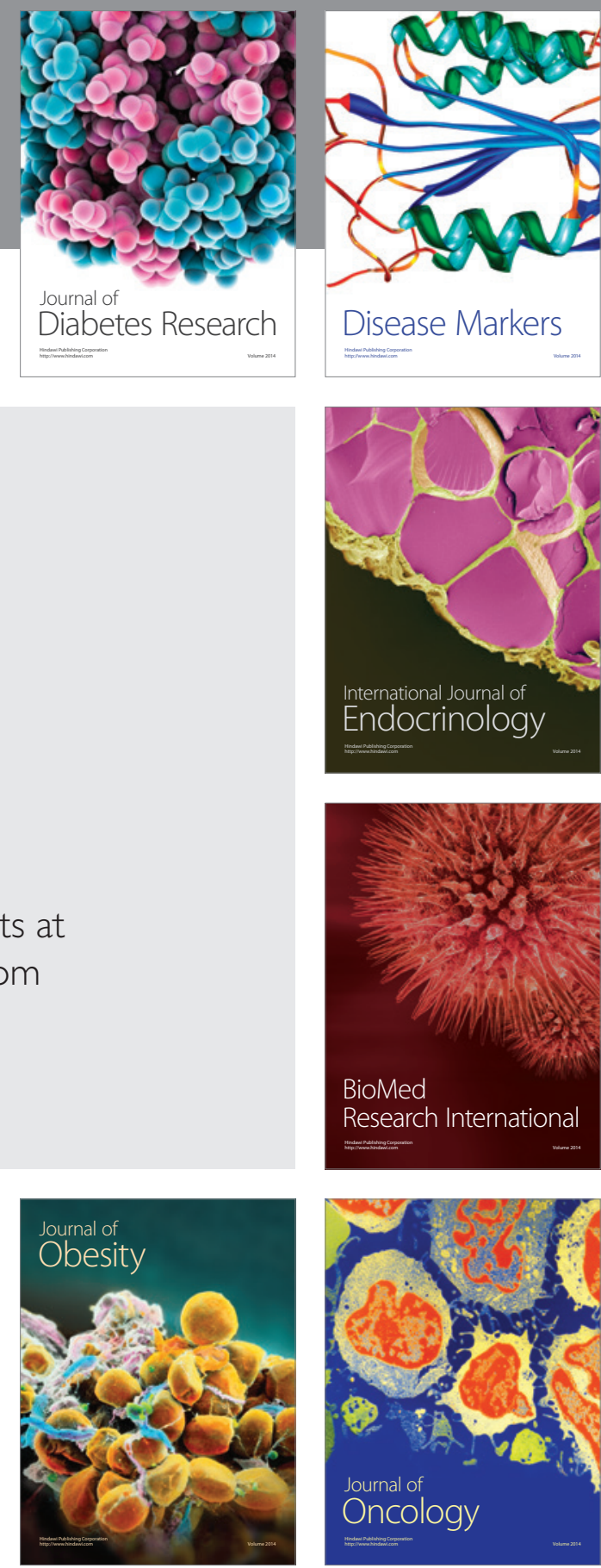

Disease Markers
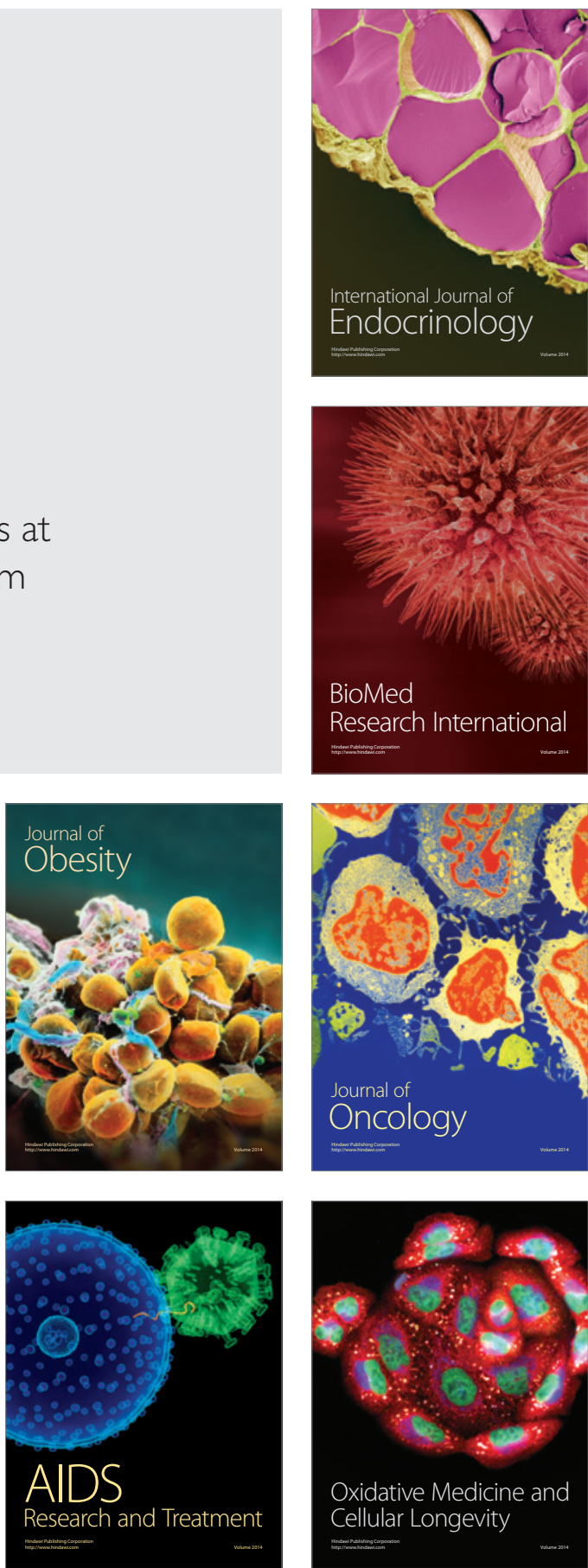